\title{
CAMPOS MÉDIOS E PROCESSOS FÍSICOS ASSOCIADOS AO CICLO DE VIDA DA BAIXA DO CHACO
}

\author{
MARCELO ENRIQUE SELUCHI ${ }^{1}$ E RENÉ DARIO GARREAUD ${ }^{2}$ \\ ${ }^{1}$ Centro de Previsão de Tempo e Estudos Climáticos, Instituto Nacional de Pesquisas Espaciais (CPTEC/ \\ INPE), Centro Nacional de Monitoramento e Alertas de Desastres Naturais (CEMADEN), Cachoeira \\ Paulista, SP, Brasil, \\ ${ }^{2}$ Departamento de Geofísica, Universidad de Chile, Santiago, Chile \\ marcelo.seluchi@cemaden.gov.br,rgarreau@dgf.uchile.cl
}

Recebido Agosto de 2011 - Aceito Abril de 2012

\begin{abstract}
RESUMO
A Baixa do Chaco $(\mathrm{BCH})$ é um sistema característico da estação chuvosa e um dos componentes das Monções da América do Sul. O presente trabalho analisa aspectos ainda não definidos da $\mathrm{BCH}$, como seu ciclo de vida e os processos físicos associados, assim como, o papel que este sistema desempenha na circulação atmosférica. O estudo tem como foco os meses de verão e utiliza as reanálises elaboradas com o modelo Eta/CPTEC (2000-2004). A metodologia se baseia na escolha de três mínimos e máximos de pressão no ponto $22^{\circ} \mathrm{S}, 60^{\circ} \mathrm{W}$ para cada mês do período analisado, a partir dos quais se realizaram compostos dos casos "baixos" e "altos".

O ciclo de vida da $\mathrm{BCH}$ está relacionado com a passagem de uma perturbação de tipo frontal, de escala sinótica ou maior, que afeta especialmente a baixa troposfera. A variabilidade da $\mathrm{BCH}$ está associada a fortes anomalias de temperatura, vento e umidade em boa parte da porção tropical e subtropical da América do Sul. Existe também uma clara relação entre a BCH e outros sistemas típicos dessa região, como a Zona de Convergência do Atlântico Sul, a Baixa do Noroeste Argentino e o Jato de Baixos Níveis. A BCH desenvolve-se, em média, devido à ocorrência de precipitação convectiva e à presença de céu claro, enquanto que sua dissipação está ligada à advecção fria pós-frontal.
\end{abstract}

Palavras-Chave: Baixa do Chaco, ciclo de vida, Baixa térmica

\begin{abstract}
MEAN FIELDS AND PHYSICAL PROCESSES ASSOCIATED WIHT THE CHACOLOW LIFECYCLE

The Chaco Low (CHL) is a typical feature of the rainy season and an important component of the South American Monsoon System. In this work we describe several aspects of the Chaco Low do not define yet, including its lifecycle and associated processes, as well as its role on the continental-scale circulation. The study focuses on the summer months using the ETA-CPTEC reanalysis (2000-2004). A composite of "high" and "low" CHL stages was performed using three monthly cases of maximum and minimum surface pressure at $22^{\circ} \mathrm{S}-60^{\circ} \mathrm{W}$.

The CHL lifecycle is related with the passage of a frontal-like disturbance of synoptic scale (or larger) affecting the lower troposphere, and occurs in concert with strong anomalies of temperature, wind and moisture over tropical/subtropical South America. There is also a clear connection between the CHL and other regional systems such as the South Atlantic Convergence Zone, the Northwestern Argentinean Low and the Low Level Jet. The deepening of the low is related with the occurrence of convective precipitation and clear skies, while the weakening of the low is mainly due to post frontal cold advection.
\end{abstract}

Keywords: Chaco Low, lifecycle, thermal low 


\section{INTRODUÇÃO}

Durante a estação chuvosa da América do Sul, que ocorre aproximadamente entre os meses de outubro e abril, os campos de circulação da baixa troposfera se caracterizam pela presença de uma ampla área de baixa pressão que, a leste dos Andes, estende-se desde a Amazônia até o noroeste da Argentina (Satyamurty et al., 1998). Devido a seu caráter quase permanente, essa baixa pode ser facilmente identificada nos mapas médios de verão (ver Figura 1), nos quais aparece como uma extensa e fraca depressão atmosférica que resulta da junção de dois sistemas diferentes. O primeiro deles localiza-se no noroeste da Argentina, aproximadamente em $30^{\circ} \mathrm{S}$, e é conhecido na literatura como a Baixa do Noroeste Argentino (BNOA), ou baixa termo-orográfica do Noroeste Argentino. O segundo centro se posiciona aproximadamente entre $15-25^{\circ} \mathrm{S}$ e $60-65^{\circ} \mathrm{W}$, nas planícies conhecidas como "região do Chaco", entre a Bolívia e o Paraguai, pelo que é usualmente identificada como a Baixa do Chaco $(\mathrm{BCH})$.

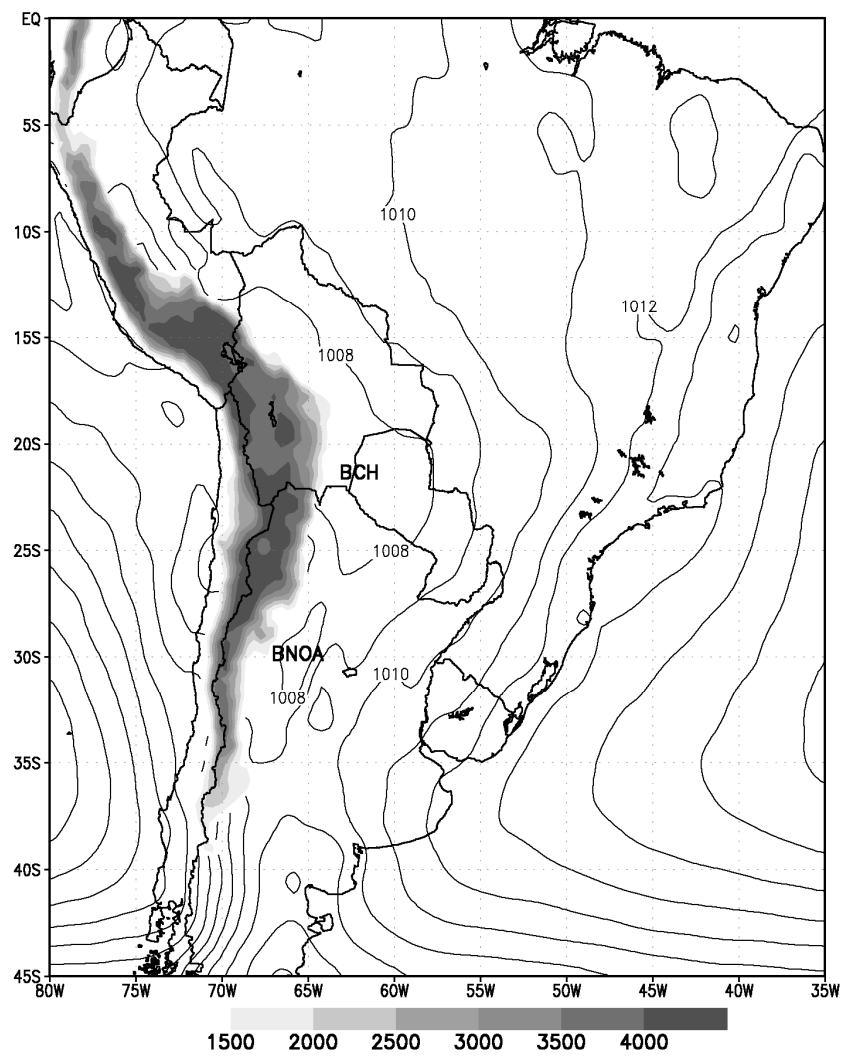

Figura 1 - Campo médio da pressão ao nível do mar (hPa, intervalo $2 \mathrm{hPa}$ ) obtida a partir das reanálises do modelo Eta/CPTEC para os meses de verão (dezembro a janeiro) do período 2000-2004. A Baixa do Noroeste Argentino e a Baixa do Chaco estão identificadas pelos símbolos "BNOA" e "BCH", respectivamente. Os tons de cinza representam a altura $(\mathrm{m})$ da topografia.
A BNOA tem sido identificada há décadas por Schwerdtfeger (1954) e analisada por diversos autores, entre os quais se destacam Lichtenstein (1980), Seluchi et al. (2003) e Ferreira (2008). Em particular Lichtenstein (1980) mostrou que a BNOA atua de forma praticamente permanente durante o verão, porém adquirindo um comportamento altamente intermitente durante o inverno. Isso se deve aos processos físicos que explicam a sua formação e variabilidade que, segundo Seluchi al. (2003), incluem fundamentalmente o balanço de radiação em superfície e a subsidência orográfica forçada. Em consequência, os fortes fluxos superficiais de calor sensível durante o verão (o noroeste da Argentina é uma região semidesértica) motivam a sua presença e persistência, enquanto que a subsidência orográfica forçada (vinculada à atividade transiente) modula sua intensidade no verão e constitui o principal mecanismo de formação durante o inverno. A BNOA apresenta um claro ciclo de vida, independentemente da época do ano (como mostrado em Ferreira, 2008), atingindo a sua máxima intensidade imediatamente antes da passagem de um sistema frontal frio, e se dissipando após a sua passagem como consequência do esfriamento advectivo.

A BCH, objeto deste trabalho, tem sido muito menos estudada na literatura, provavelmente devido à pouca cobertura de dados sobre a região que ocupa e à dificuldade que as análises globais de baixa resolução têm para detectá-la e identificá-la. Como primeiro antecedente pode-se citar novamente o trabalho de Schwerdtfeger (1954), que na sua Figura 8, correspondente ao campo médio de pressão de verão para o período 1939 1948, identificou um centro de baixa pressão localizado entre o norte da Argentina e o sul do Paraguai e da Bolívia. Contudo, esse autor não mencionou nem denominou esse sistema. Só recentemente, Seluchi e Saulo (2010) pesquisaram algumas características da $\mathrm{BCH}$ e analisaram os processos físicos que a originam através do estudo de dois casos particulares. Esses autores mostraram que a variabilidade da $\mathrm{BCH}$ responde basicamente às variações na espessura relativa $250 / 1000 \mathrm{hPa}$, que modularia a intensidade tanto da $\mathrm{BCH}$, quanto da Alta da Bolívia. Em outras palavras, o aquecimento da camada 250/1000 $\mathrm{hPa}$, e o consequente aumento de sua espessura, motivaria a simultânea intensificação da BCH e da Alta de Bolívia. Dentre os principais processos físicos responsáveis por esse aquecimento no caso de verão, Seluchi e Saulo (2010) sugerem a liberação de calor latente pela convecção, mecanismo que foi previamente identificado por Lenters e Cook (1999) como causa principal do desenvolvimento da Alta da Bolívia. O balanço de calor na superfície teria também uma contribuição positiva, embora comparativamente menor, e um papel muito importante como disparador da convecção. Tais conclusões apontam a BCH como um sistema ligado às Monções da América do Sul (Vera et al., 2006). No caso da primavera, os autores detectaram 
uma contribuição menor da liberação de calor latente pela precipitação, mas esse fato foi compensado pela presença de subsidência de grande escala.

A proximidade geográfica da $\mathrm{BNOA}$ e da $\mathrm{BCH}$, assim como a relativa semelhança entre os processos que as originam (o aquecimento superficial e a subsidência), dificultam frequentemente a sua distinção. Entretanto, existem várias diferenças entres estes sistemas, discutidas em Seluchi e Saulo (2012), que incluem o tipo de massa de ar na qual se desenvolvem, sua estrutura dinâmica e termodinâmica, sua relação com os transientes e sua variabilidade diurna. Em particular, a $\mathrm{BCH}$ se localiza dentro de uma massa de ar de características tropicais e altamente propensa à atividade convectiva. Diferentemente da BNOA, a BCH se posiciona normalmente ao norte do jato subtropical e é pouco influenciada pela atividade transiente. A variabilidade diurna da pressão, temperatura e umidade relativa no seu âmbito é também menor que a observada na região que ocupa a BNOA. Contudo, muitos aspectos da $\mathrm{BCH}$ são ainda essencialmente desconhecidos: seu papel na circulação dos baixos níveis não tem sido ainda documentado, seu ciclo de vida é essencialmente desconhecido e sua relação com outros sistemas típicos das monções da América do Sul não tem sido devidamente aprofundada.

O objetivo deste trabalho é estudar o ciclo de vida da $\mathrm{BCH}$ e identificar os padrões de circulação típicos dos períodos ativos e inativos deste sistema. A partir dos campos resultantes se pretende analisar o papel da $\mathrm{BCH}$ na circulação atmosférica, especialmente na baixa troposfera, assim como estabelecer o impacto da sua atuação nos campos de variáveis relevantes, como temperatura, vento, umidade e precipitação.

\section{DADOS E METODOLOGIA}

$\mathrm{O}$ trabalho concentra-se nos meses de verão (dezembro a fevereiro), já que esse é o período durante o qual a $\mathrm{BCH}$ se encontra mais desenvolvida (ver Figura 1). Os dados utilizados foram as reanálises regionais sobre América do Sul elaboradas com o modelo regional Eta/CPTEC, que cobrem o período 2000-2004, resultantes do experimento descrito em Aravéquia et al. (2008), Herdies et al. (2008) e Andreoli et al. (2008). Em particular, a variável precipitação acumulada do horário 0000 UTC corresponde ao valor acumulado nas 12 horas prévias e posteriores a esse horário (totalizando 24 horas), obtido segundo a metodologia descrita em Aravéquia et al. (2008). Entre as principais vantagens desta análise se destacam o emprego da coordenada vertical eta (através do modelo regional Eta/CPTEC), que se mostra especialmente adequada em regiões com topografia íngreme como a Cordilheira dos Andes (Messinger, 1984). Por outro lado, as reanálises possuem uma boa resolução horizontal, vertical e temporal $(40 \mathrm{~km}, 38$ níveis e 3 h, respectivamente) e oferecem um grande número de variáveis (59).

Com a finalidade de caracterizar o ciclo de vida da $\mathrm{BCH}$ foram selecionadas datas nas quais esse sistema apresentasse intensidade relativa máxima e mínima, com o objetivo de analisar seu comportamento em diferentes estágios de evolução. Os casos foram selecionados utilizando a série de pressão reduzida ao nível do mar no ponto $22^{\circ} \mathrm{S}$ e $60^{\circ} \mathrm{W}$ (próximo da posição média da $\mathrm{BCH}$, ver Figura 1) do horário 0000 UTC, correspondente aos meses de verão do período disponível (20002004). O horário 0000 UTC foi preferido por ser o mais próximo, em média, ao momento em que a $\mathrm{BCH}$ atinge a sua máxima intensidade (Seluchi e Saulo 2012). A partir dessa série foram escolhidos três máximos e três mínimos relativos de pressão para cada mês do período descrito, como se exemplifica na Figura 2 para um mês particular. Foi estabelecido que os máximos e mínimos consecutivos deviam apresentar uma separação mínima de 3 dias para permitir uma certa independência entre os casos. A quantidade de máximos e mínimos relativos mensais foi arbitrariamente fixada em três (número relativamente baixo e, portanto, sempre possível), para garantir que todos os meses/ anos tivessem o mesmo número de casos.

A partir da metodologia adotada foram obtidos dois conjuntos de 45 casos, onde a pressão atmosférica apresentou intensidade mínima e máxima na região de atuação da $\mathrm{BCH}$, denominados respectivamente como dias B0 e A0. Para caracterizar o ciclo de vida da $\mathrm{BCH}$, foi realizada uma composição de casos dos dias B0 e A0, assim como dos dias imediatamente anteriores e posteriores a eles, denominados B-1, B1, A-1 e A1, respectivamente. Para fins de simplificação, denominaremos casos "baixos" ("altos") ao conjunto dos dias B0 (A0).

Os campos de anomalias foram obtidos como a diferença com respeito à média correspondente aos meses de verão (Dezembro a Fevereiro) do período 2000-2004 (0000 UTC).

Os processos físicos associados ao ciclo de vida da $\mathrm{BCH}$ foram analisados qualitativamente utilizando a equação termodinâmica. O emprego desta equação justifica-se em função dos antecedentes citados na introdução, e dos resultados que serão mostrados na seção 3.3 , já que existe uma conexão entre as variações de pressão no âmbito da $\mathrm{BCH}$ e a variabilidade da temperatura (ou espessura) na camada $500 / 1000 \mathrm{hPa}$. A equação termodinâmica pode assim ser escrita:

$$
\frac{\partial T}{\partial t}=-V \cdot \nabla T+\omega(\gamma d-\gamma)+R(1)
$$

onde $\mathrm{T}$ é a temperatura, $\mathrm{V}$ o vento horizontal, $₫$ a componente vertical do vento, $\gamma \mathrm{d}$ o gradiente vertical seco, $\gamma$ o gradiente vertical da temperatura $\mathrm{e} \mathrm{R}$ as fontes diabáticas de calor, que incluem os processos de mudanças de fase (como o calor latente 


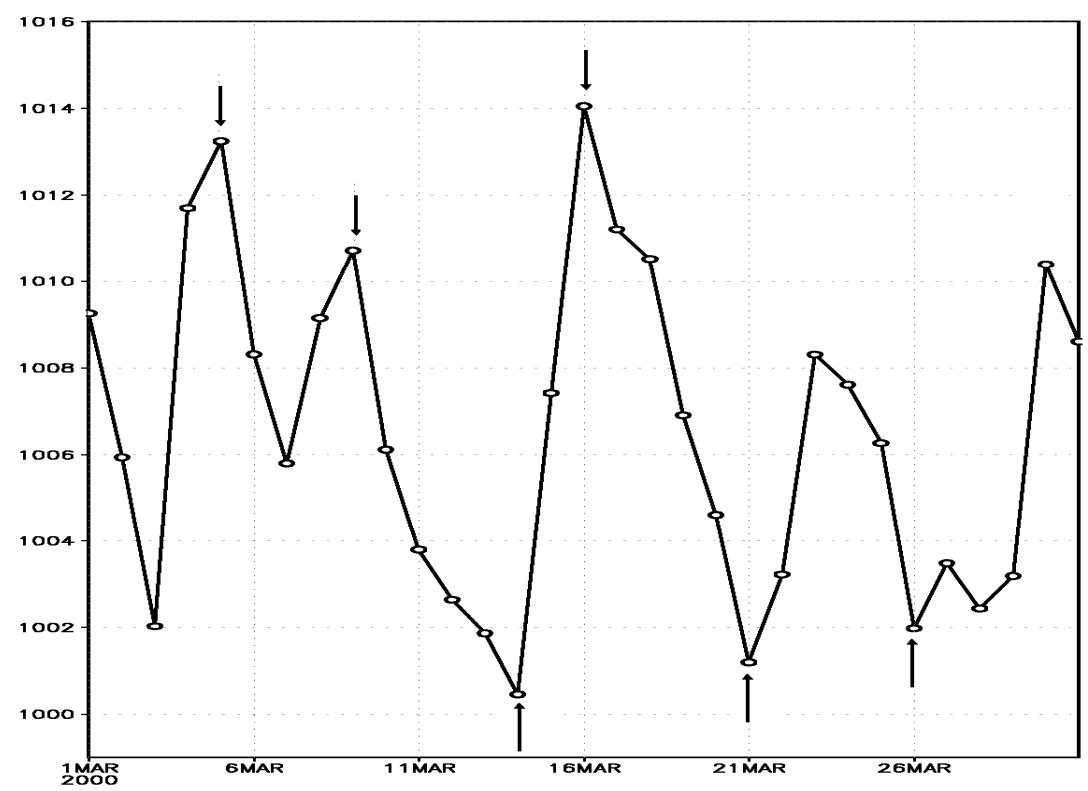

Figura 2 - Série de pressão reduzida ao nível médio do mar (hPa) no ponto $22^{\circ} \mathrm{S} 60^{\circ} \mathrm{W}$ (0000 UTC) extraída das reanálises do modelo Eta/CPTEC para o mês de março de 2000. As setas exemplificam os máximos e mínimos relativos de pressão escolhidos nesse mês para serem incluídos no conjunto de casos A0 e B0, respectivamente.

liberado pela precipitação) e os fluxos de calor. Os dois primeiros termos da direita da equação foram calculados utilizando as reanálises do modelo Eta, enquanto que o terceiro foi estimado qualitativamente através de variáveis indiretas. Por essa razão, os resultados têm apenas valor qualitativo. Com fins práticos, a adveccção horizontal de temperatura foi obtida no nível de 925 $\mathrm{hPa}$ e o termo adiabático foi integrado na camada $500 / 900 \mathrm{hPa}$, para o qual foi considerado o valor de $₫$ nos níveis disponíveis, entre 850 e $500 \mathrm{hPa}$, e as temperaturas nos níveis imediatamente superiores e inferiores. Os termos diabáticos foram estimados de forma qualitativa através de variáveis indiretas, como precipitação e nebulosidade.

\section{RESULTADOS}

\subsection{Identificação do ciclo de vida}

A Figura 3 apresenta os campos médios de pressão, assim como sua anomalia correspondente para os dias B-1, B0 e B1 (acima) e A-1, A0 e A1 (abaixo). Em primeiro lugar, a Figura 3 permite identificar claramente um ciclo de vida, onde a máxima intensidade da $\mathrm{BCH}$, no dia $\mathrm{B} 0$, está ligada à passagem de uma perturbação ciclônica. Essa perturbação afeta principalmente as latitudes médias, especialmente no dia B-1, e se desloca para o norte imediatamente a leste dos Andes, denotando uma influência orográfica (Gan e Rao, 1994). Pelo contrário, no dia $\mathrm{A} 0$ a $\mathrm{BCH}$ está ausente em virtude da passagem de uma perturbação anticiclônica, que apresenta um comportamento quase simétrico em relação aos casos "baixos". Em particular, pode ser notada certa "sequência" entre as figuras do painel superior e inferior, considerando que, por exemplo, o padrão associado ao dia $\mathrm{B} 1$ resulta relativamente semelhante ao correspondente ao dia A-1, fato que reforça o conceito de "ciclo de vida".

Uma análise mais detalhada mostra que durante o dia B-1 as maiores anomalias negativas de pressão se localizam muito próximas da posição climatológica da BNOA (Ferreira, 2008), sugerindo que o aprofundamento da BNOA constitui um passo prévio, com uma defasagem média de um dia, à intensificação da $\mathrm{BCH}$. Durante o dia B0 a anomalia negativa de pressão, provavelmente associada a uma perturbação frontal devido a sua característica migratória, se posiciona na região ocupada pela $\mathrm{BCH}$, enquanto que a pressão aumenta na região normalmente ocupada pela BNOA em decorrência da aproximação de um anticiclone pós-frontal.

No composto de casos A0 (Figura 3e) a BCH está ausente e é substituída por uma crista, que teria características pós-frontais em função da natureza migratória das anomalias de pressão (ver Figuras 3a a 3f). Na região do Pantanal as isóbaras mostram em média uma fraca circulação ciclônica, possivelmente associada à perturbação frontal. Em termos de anomalias, existe uma simetria quase perfeita entre os dias B0 e A0.

A Figura 4 apresenta os campos médios de linhas de corrente e de anomalias de altura geopotencial no nível de $250 \mathrm{hPa}$, para os casos "baixos" e "altos", na qual aparecem 
c) $\mathrm{B}-1$

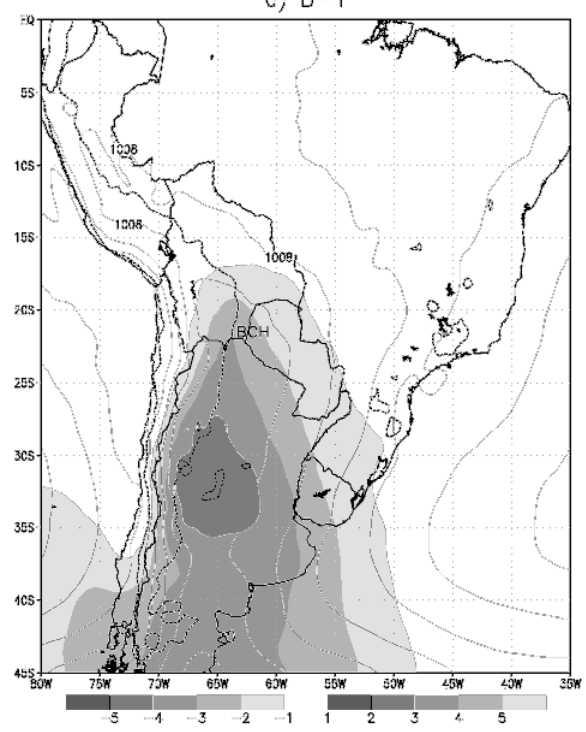

d) $A-1$

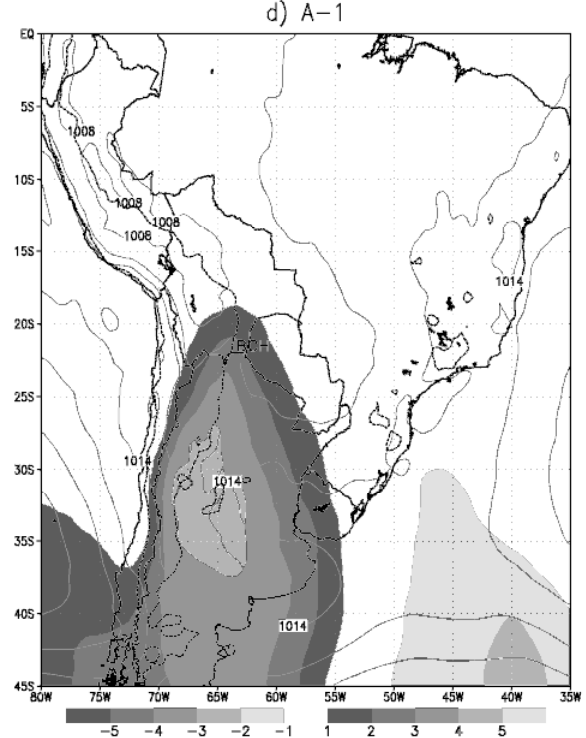

b) $\mathrm{BO}$

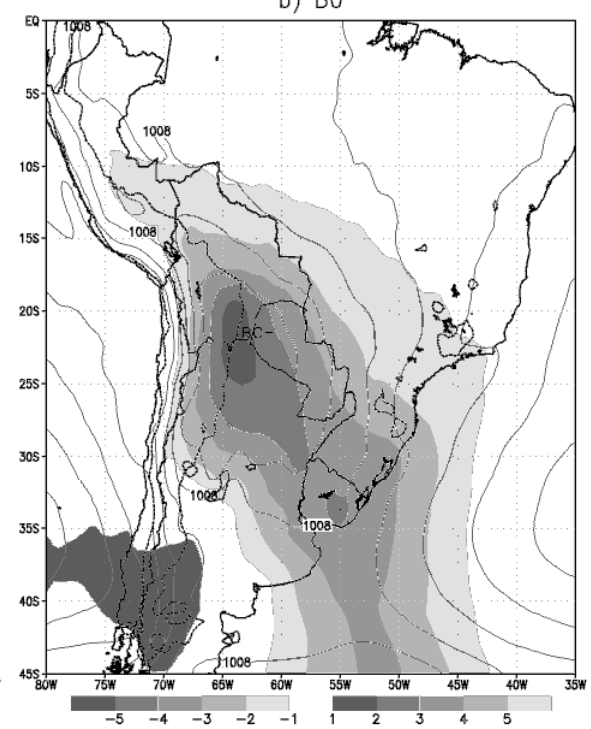

e) $\mathrm{AO}$

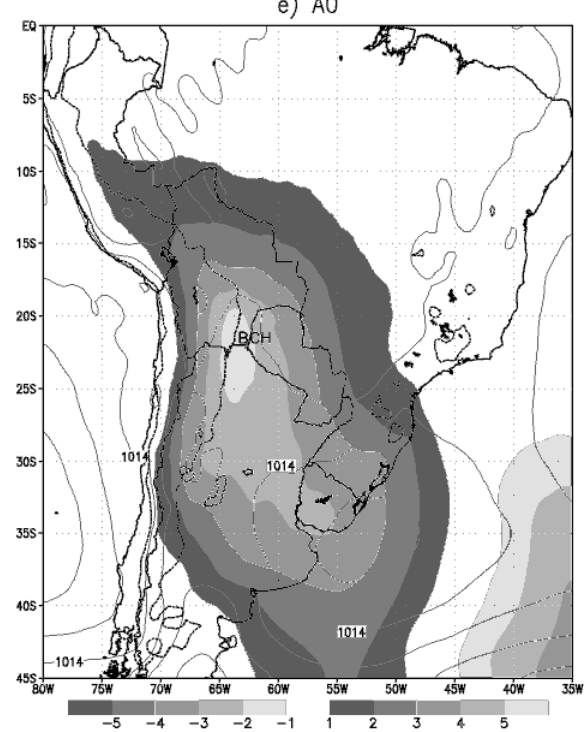

c) B1

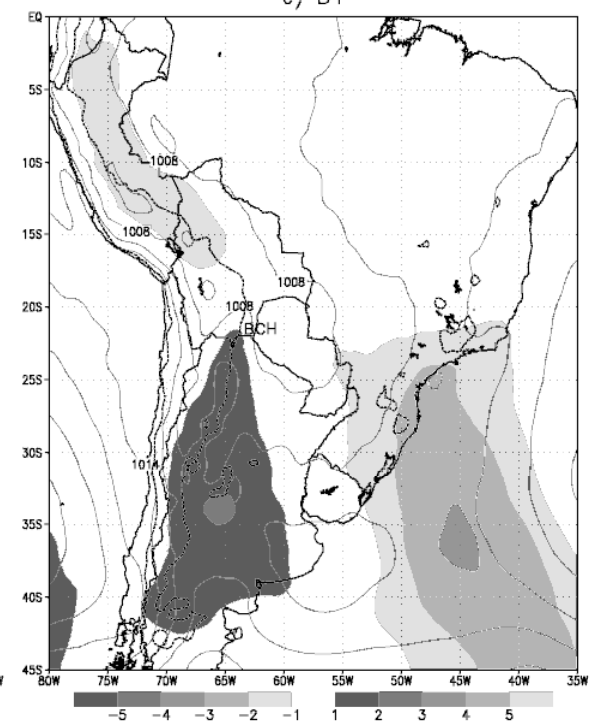

f) $\mathrm{A} 1$

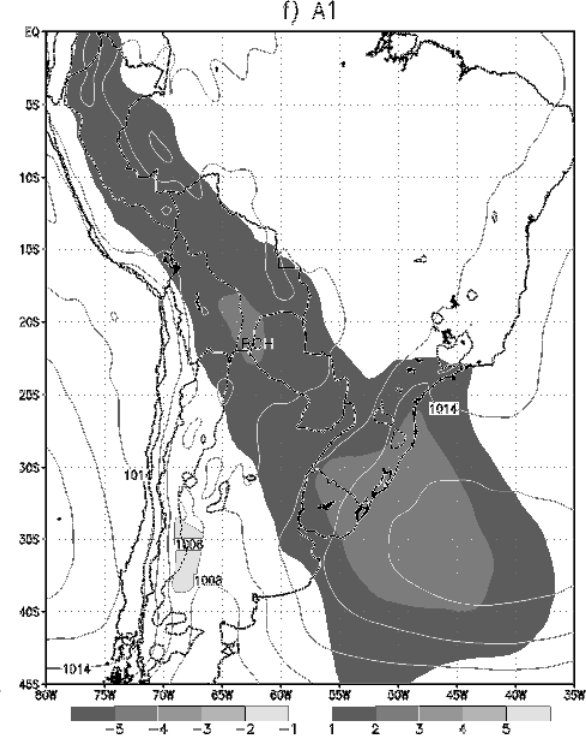

Figura 3 - Campos médios de pressão reduzida ao nível médio do mar (hPa, contornos, intervalo $2 \mathrm{hPa}$ ) e suas anomalias com relação a média do período 2000-2004 (hPa, tons de cinza) para os compostos a) B-1, b) B0, c) B1, d) A-1, e) A0 e f) A1. A linha pontilhada delimita a altura topográfica de $700 \mathrm{~m}$.

novamente evidências claras da presença de uma onda de escala sinótica, especialmente nas latitudes médias. A perturbação se manifesta fundamentalmente através das alterações na curvatura da circulação nas latitudes subtropicais, assim como da presença de ondas extratropicais de fase oposta ao sul de $30^{\circ} \mathrm{S}$ em ambos os painéis da Figura 4. A distância entre os centros anômalos positivos e negativos nas latitudes médias (por exemplo, em torno dos $45^{\circ} \mathrm{S}$ ) sugere que a perturbação está associada a um número de onda 5-6, vinculada espacialmente à escala sinótica ou maior. Em particular, no composto B0 (Figura 4a) a Alta da Bolívia se encontra próxima da sua posição normal e os ventos apresentam forte curvatura anticiclônica na região onde se localiza a BCH. Além disso, a circulação mostra uma forte difluência na região de atuação da Zona de Convergência do Atlântico Sul (ZCAS) (Carvalho e Jones, 2009) favorecendo o levantamento do ar nessa área. No composto do dia A0 (Figura 4b) o Anticiclone da Bolívia está deslocado para leste, estendendo uma forte crista sobre a região sudeste do Brasil, que gera uma fraca confluência do fluxo em torno de $10-20^{\circ} \mathrm{S}$. Outra diferença importante com respeito ao composto B0 (mostrado na Figura 4a) é a presença, em média, de um vórtice ciclônico de altos níveis sobre a costa nordeste, sugerindo um comportamento diferencial no regime de precipitações (Kousky e Gan, 1981). 
a) $\mathrm{BO}$

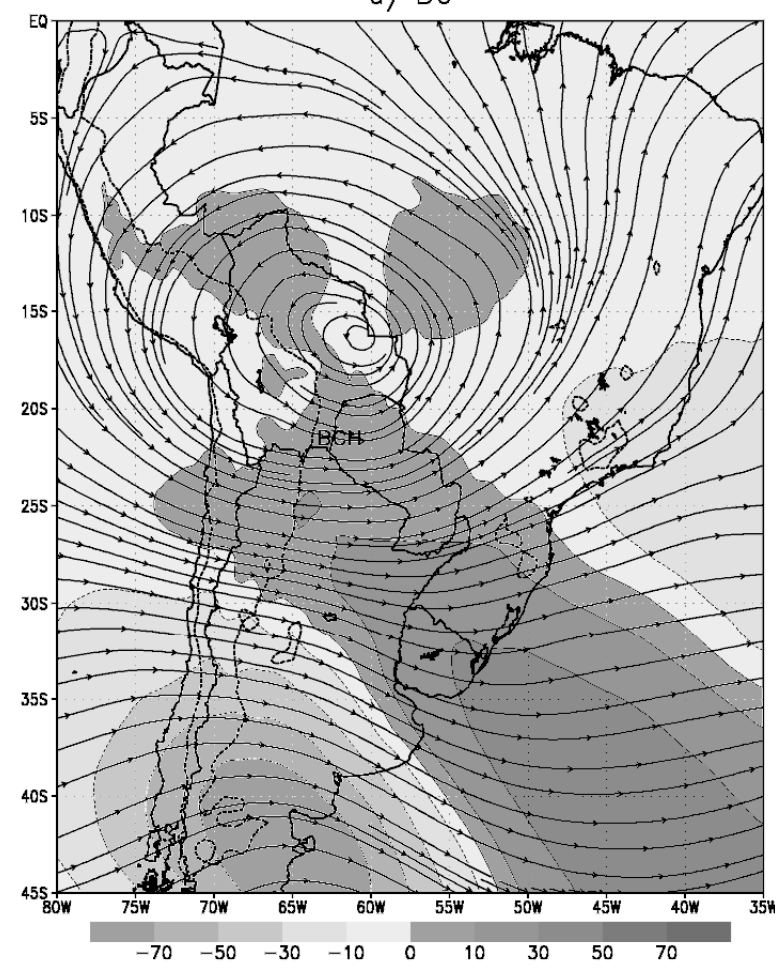

b) $\mathrm{AO}$

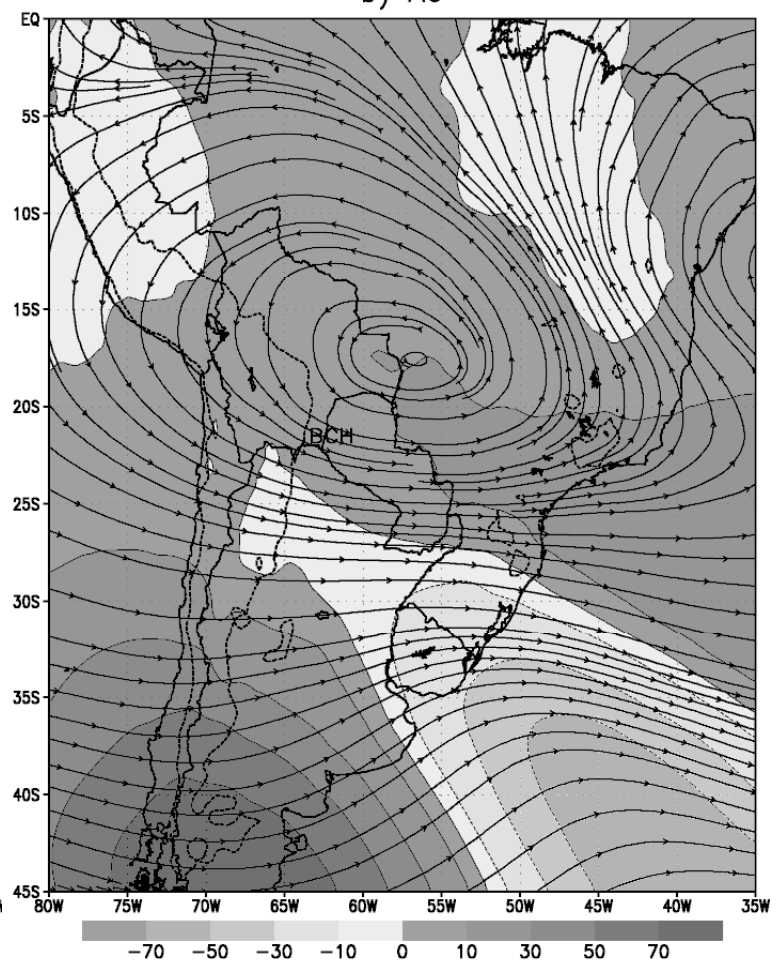

Figura 4 - Campos médios de linhas de corrente e anomalias de altura geopotencial ( $\mathrm{m}$, tons de cinza) no nível de 250 hPa para os compostos a) B0 e b) A0. A linha pontilhada delimita a altura topográfica de $700 \mathrm{~m}$.

\subsection{Características dos períodos com $\mathrm{BCH}$ intensificada e inibida}

Para analisar o papel da BCH no contexto das Monções da América do Sul e pesquisar de que forma as variações na sua intensidade impactam nas características dinâmicas e termodinâmicas da região, são apresentados em seguida diversos campos meteorológicos de interesse para os compostos "baixos" e "altos". Em todos os casos as anomalias foram obtidas com respeito a media de verão (dezembro-fevereiro) dos anos 2000 a 2004 (horário 0000UTC).

A Figura 5 mostra as anomalias de temperatura potencial equivalente (TPE) e de vento no nível de $925 \mathrm{hPa}$. No composto "baixo" (Figura 5a) resulta evidente a presença de uma perturbação frontal com orientação NO-SE, que se estende desde o noroeste da Argentina, ao sul de $25^{\circ} \mathrm{S}$, até o Oceano Atlântico. Essa frente separa duas massas de ar com características diferentes, já que as anomalias de TPE apresentam um contraste de mais de 10 graus entre a região ocupada pela $\mathrm{BCH}$ e a Patagônia, com um gradiente horizontal máximo em torno de $25-35^{\circ} \mathrm{S}$. Nota-se que no dia B0 (Figura 5a) as anomalias de TPE podem atingir quase 10 graus no âmbito da $\mathrm{BCH}$ (se estendem com menor intensidade ao centro-sul do Brasil), o que resulta coerente com o caráter térmico desta baixa. Além disso, a presença de um gradiente térmico negativo (temperatura aumentando na direção sul) na região central do Brasil é uma característica comumente observada na pré-estação chuvosa da monção sul-americana (Gan, et al., 2004). Por outro lado, existe uma forte convergência de massa associada à região frontal, particularmente sobre o continente e a leste dos Andes. Uma característica destacada é o aumento da velocidade do vento de norte desde latitudes equatoriais, que atinge uma intensidade máxima imediatamente a leste da $\mathrm{BCH}$. Neste sentido, a intensificação da $\mathrm{BCH}$ parece ter um papel muito importante não só na modificação da circulação atmosférica na baixa troposfera, como também no desenvolvimento dos Jatos de Baixos Níveis (Salio et al., 2002 e referências citadas). Em contraposição, nos casos "altos" (Figura 5b) a temperatura é marcadamente mais baixa que nos casos B0 (mais de 15 graus), apresentando anomalias negativas de mais de 8 graus. Nesses casos a região do Chaco é afetada por ventos com curvatura anticiclônica e componente de sul. A frente fria, localizada aproximadamente sobre a região litorânea de Rio de Janeiro, se destaca fundamentalmente pela intensidade da massa fria pósfrontal, em contraste com a Figura 5a, onde a massa quente da vanguarda resulta comparativamente mais anômala.

A Figura 6 permite fazer um diagnóstico do campo de precipitação e do transporte de umidade no nível de 925 
a) $\mathrm{BO}$

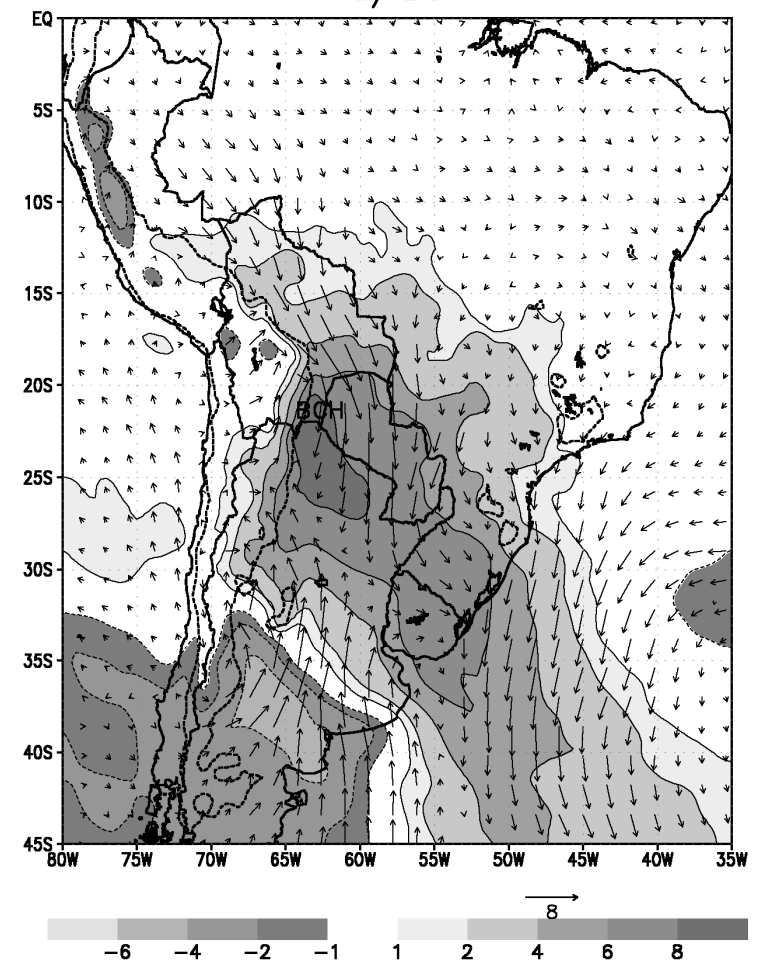

b) $\mathrm{AO}$

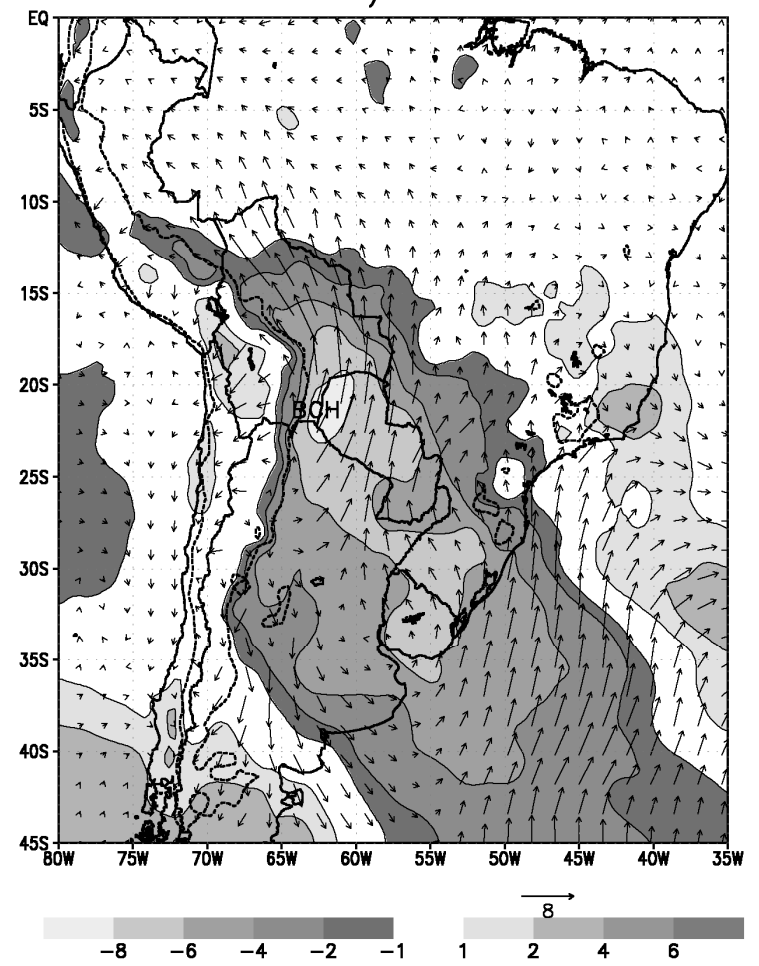

Figura 5 - Campos médios de vento $(\mathrm{m} / \mathrm{s})$ e de anomalias de temperatura potencial equivalente (K, tons de cinza) no nivel de y 25 hra para os compostos a) B0 e b) A0. A linha pontilhada delimita a altura topográfica de $700 \mathrm{~m}$.

hPa. Nota-se que a frente fria identificada na Figura 5a está associada, em média, à ocorrência de precipitações no Uruguai, norte da Argentina e sul do Brasil, o que poderia ter valor prognóstico e ofereceria um dado interessante, principalmente para a região noroeste da Argentina que se caracteriza pela baixa pluviosidade. A forte convergência do transporte de umidade, assim como a atuação da perturbação ciclônica nos altos níveis (visível na Figura 4a sobre o centro-oeste da Argentina) seriam as causas principais das anomalias positivas de chuva. No sul da região Amazônica, onde se observa uma difluência anômala, tanto no campo de vento (Figura 5a) quanto no transporte de umidade (Figura 6a), as anomalias de precipitação resultam negativas. Um aspecto relevante são as anomalias positivas de precipitação sobre grande parte das regiões norte, nordeste e sudeste do Brasil, que se estendem inclusive sobre o Oceano Atlântico. Esse padrão, provavelmente associado à forte difluência dos ventos nos altos níveis (ver Figura 4a), sugere uma possível relação entre a intensificação da BCH e a presença da ZCAS. Essa afirmação é coerente com os resultados encontrados por Paegle e Mo (1997), que identificaram uma relação de tipo dipolo entre as latitudes de atuação da ZCAS e a Bacia do Prata.

Nos casos "altos" (Figura 6b), apesar das anomalias negativas de TPE observadas na Figura 5b, não se identificam anomalias negativas de precipitação no âmbito da $\mathrm{BCH}$ nem no noroeste da Argentina. Novamente, isso pode ser devido parcialmente à baixa pluviosidade desta última região. Entretanto, as anomalias positivas de chuva são bem evidentes nas proximidades da frente fria, coerentes com a convergência de massa detectada na Figura 5b, e com a presença de uma fraca convergência no transporte de umidade (Figura 6b). Outro detalhe destacável são as anomalias negativas de chuva que se estendem do norte do Brasil em direção ao sudeste, sugerindo que nesses casos a ZCAS encontra-se inibida. Essa característica, que poderia estar relacionada à ocorrência de subsidência pré-frontal compensatória, confirma novamente a relação entre a $\mathrm{BCH}$ e a ZCAS, assim como a presença de uma perturbação de escala regional/continental.

Do ponto de vista da estrutura vertical, a Figura 7 ilustra a seção vertical das anomalias de temperatura potencial (sombreado) e da altura geopotencial na latitude $22^{\circ} \mathrm{S}$ para ambos os compostos. Em ambos os casos (Figuras 7a e 7b) as anomalias de temperatura potencial e altura geopotencial apresentam sinais contrários, evidenciando um acoplamento de fase oposta entre a onda térmica e de massa (baixa quente na Figura 7a e alta fria na Figura 7b). Em particular, as anomalias negativas de altura geopotencial, associadas às anomalias positivas de temperatura na Figura 7a, ratificam o caráter térmico da $\mathrm{BCH}$. 
a) $\mathrm{BO}$

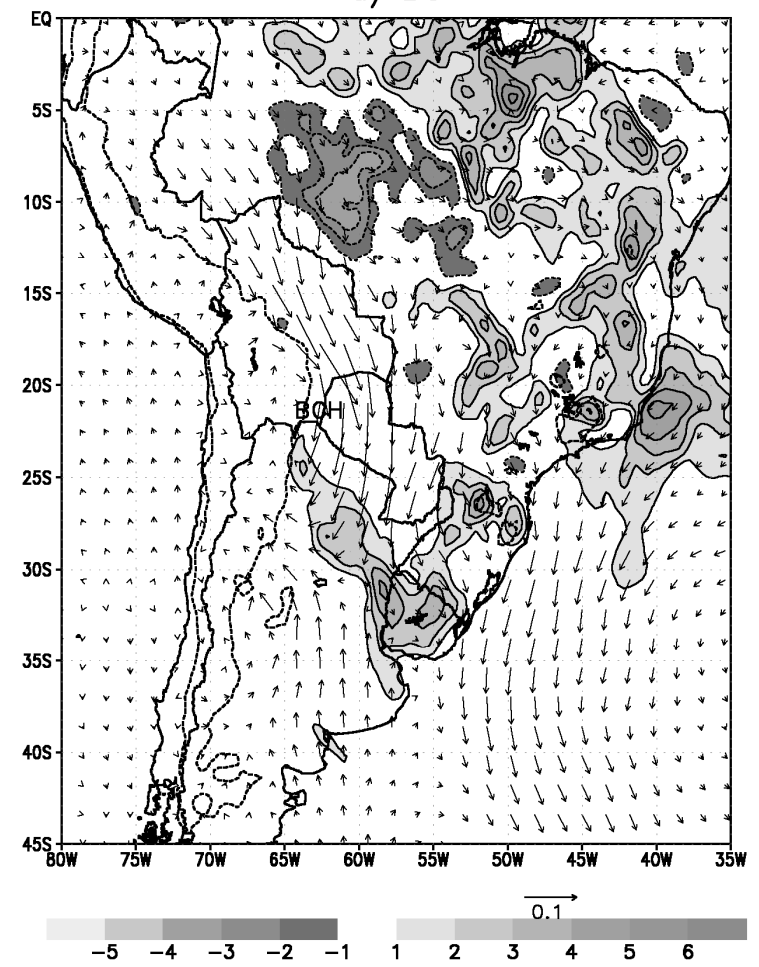

b) $\mathrm{AO}$

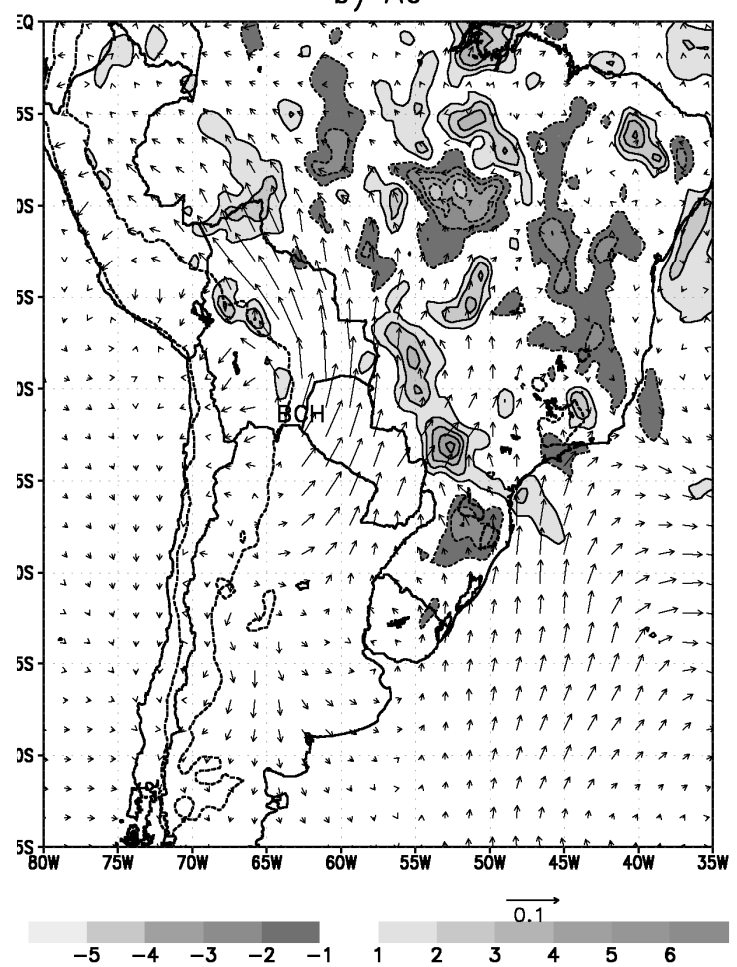

Figura 6 - Campos médios de anomalias de precipitação ( $\mathrm{mm}$, tons de cinza) e de transporte de umidade ( $\mathrm{m} / \mathrm{s}$, setas) no nível de $925 \mathrm{hPa}$ para os compostos a) B0 e b) A0. A linha pontilhada delimita a altura topográfica de $700 \mathrm{~m}$.

Resulta evidente também, a partir da Figura 7a, a importância da espessura 500/1000 (e, portanto, da temperatura média nessa camada) como elemento chave para explicar a variabilidade da $\mathrm{BCH}$, considerando que dentro dessa camada ocorrem as maiores anomalias de temperatura e altura geopotencial. No entanto, não se pode detectar uma anomalia de altura geopotencial de sinal oposto nos altos níveis da troposfera, como cabe esperar numa estrutura de baixa térmica. Em outras palavras, não se detecta uma relação direta entre a intensidade da $\mathrm{BCH}$ e da Alta da Bolívia. Isso pode se dever, pelo menos parcialmente, a que ambos os sistemas não são necessariamente concêntricos. Em geral, as maiores anomalias de ambas as variáveis se encontram nos níveis mais baixos (superfície para o caso da altura geopotencial e $850 \mathrm{hPa}$ para a temperatura potencial) e se amortecem com a altura. Outro ponto relevante é que as maiores anomalias estão geograficamente limitadas entre a Cordilheira dos Andes e o Planalto Central, sugerindo uma provável influência orográfica.

Como complemento aos resultados anteriores, a Figura 8 apresenta a seção vertical dos compostos de anomalias da umidade específica e da componente meridional do vento médio para os casos "baixos" e "altos". A Figura 8a mostra que a intensificação da $\mathrm{BCH}$ ocorre em simultaneidade com a atuação do Jato de Baixos Níveis (JBN), já que o composto da componente meridional do vento praticamente satisfaz, na média dos casos, o critério 1 de Bonner (1968). Esse resultado é coerente com os encontrados por Saulo et al. (2004), que identificaram ao balanço geostrófico como o principal mecanismo de intensificação dos JBNs. A relação entre a $\mathrm{BCH}$ e os JBNs tem importantes implicações práticas para a previsão meteorológica diária, visto que a atuação destes últimos tem forte impacto no tempo e clima do sudeste da América do Sul (Salio et al., 2002, Marengo et al., 2004). O máximo de vento norte está associado às anomalias positivas de umidade específica, provavelmente como resultado da advecção da Região Amazônia, que também contribui para as anomalias positivas de TPE mostradas na Figura 7a. Nos altos níveis é possível identificar a circulação vinculada à Alta da Bolívia, que apresenta mudanças na sua posição e intensidade entre os compostos B0 e A0 (comparar as Figuras 8a e 8b). No composto A0 (Figura 8 b) prevalecem os ventos de sul na baixa e média troposfera, restritos entre a Cordilheira dos Andes e o Planalto Central. Nestes casos o vento máximo se posiciona próximo do nível de $900 \mathrm{hPa}$, um pouco mais baixo do que nos casos B0. Embora o padrão de umidade não resulte muito claro, existe uma camada com anomalias negativas centrada aproximadamente nos $900 \mathrm{hPa}$, cercada por anomalias ligeiramente positivas. 
a) $\mathrm{BO}$

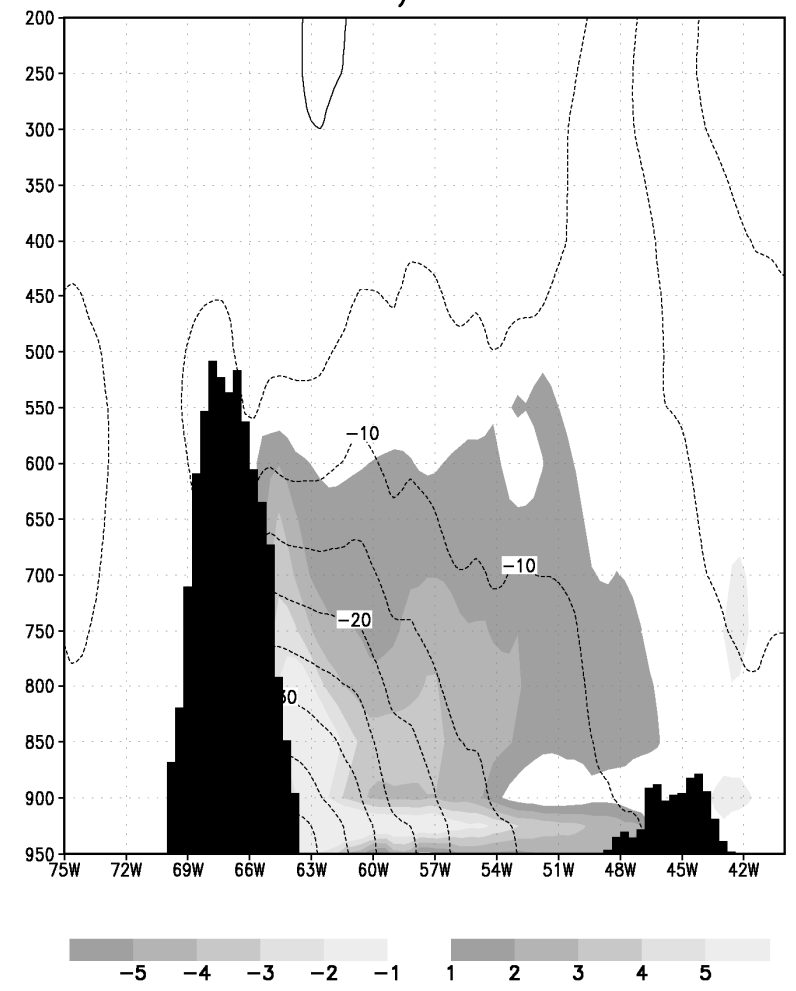

b) $\mathrm{AO}$

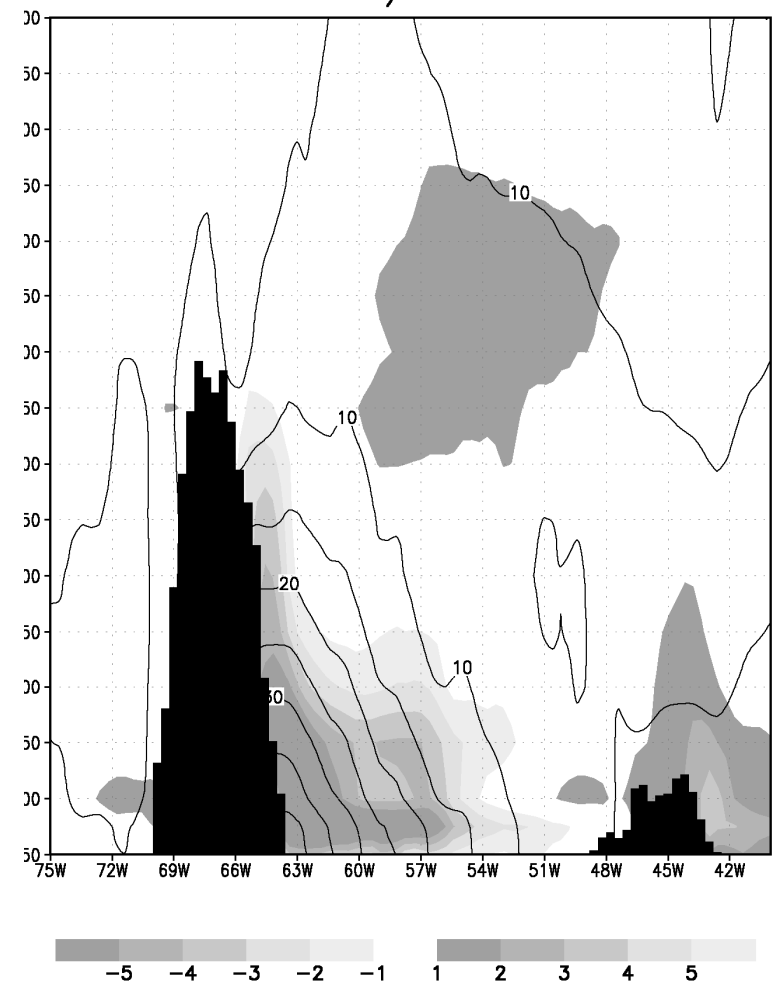

Figura 7 - Seção vertical em $22^{\circ} \mathrm{S}$ de anomalias de altura geopotencial (m, contornos, intervalo $5 \mathrm{~m}$ ) e de temperatura potencial (K, tons de cinza) para os compostos a) B0 e b) A0. O perfil da topografia é representado pela cor preta.

\subsection{Processos físicos envolvidos}

Como foi observado na Figura 7 existe uma relação estreita e de sinal oposto entre as anomalias de altura geopotencial e de temperatura na baixa e média troposfera. Essa relação também resulta fundamental para explicar o ciclo de vida da $\mathrm{BCH}$, pois, como se deduz a partir da Figura 9, as tendências de altura geopotencial no nível de $1000 \mathrm{hPa}$ (tons de cinza) estão estreitamente relacionadas com as mudanças de espessura 500/1000 hPa nas 24 horas anteriores (contornos em cinza), independentemente da fase do ciclo de vida. No composto B-1 (Figura 9a) as tendências de altura geopotencial em $1000 \mathrm{hPa}$ são máximas no âmbito da BNOA e estão estreitamente ligadas ao incremento da espessura 500/1000 hPa. Nota-se que as tendências de altura geopotencial no nível de 500 $\mathrm{hPa}$ (linhas pretas tracejadas) são pequenas ao norte de $30^{\circ} \mathrm{S}$, indicando uma escassa influência dinâmica das ondas sinóticas. A intensificação da BCH (Figura 9b) apresenta um claro caráter térmico, visto que a altura geopotencial do nível de $1000 \mathrm{hPa}$ e a espessura 500/1000 $\mathrm{hPa}$ variam de forma semelhante e com sinal oposto, enquanto que a altura geopotencial em $500 \mathrm{hPa}$ não sofre alterações significativas. Com fins de comparação, a intensificação da $\mathrm{BCH}$ devido a processos térmicos contrasta com o aumento do geopotencial em $1000 \mathrm{hPa}$ na região da Patagônia, que resulta tanto da queda da altura geopotencial em $500 \mathrm{hPa}$, quanto do esfriamento da camada 500/1000 hPa.

O processo de dissipação da $\mathrm{BCH}$ (Figura 9c) ocorre exclusivamente em decorrência do esfriamento da camada $500 / 1000 \mathrm{hPa}$, levando em conta que as variações da altura geopotencial no nível de $500 \mathrm{hPa}$ são, em média, menores do que $5 \mathrm{~m} /$ dia. Esse fato é coerente com a passagem de uma perturbação frontal, como foi mencionado anteriormente.

Com o objetivo de aprofundar o entendimento dos processos físicos associados ao ciclo de vida da $\mathrm{BCH}$, e em virtude dos resultados anteriores, é feita a seguir uma análise dos mecanismos que possam gerar variações de espessura na camada $500 / 1000 \mathrm{hPa}$. Entre eles deve-se considerar, levando em conta a equação termodinâmica (Equação 1), a advecção horizontal de temperatura, o termo adiabático e os processos diabáticos, que incluem os processos de mudança de fase (em particular o calor latente liberado pela precipitação) e os fluxos superficiais de calor. Tais mecanismos, como mencionados anteriormente, serão avaliados apenas em forma qualitativa.

A Figura 10 apresenta os campos médios de advecção horizontal de temperatura (Figura 10a) e do termo adiabático (Figura 10b), correspondentes ao dia B0. Em ambas as 
a) $\mathrm{BO}$

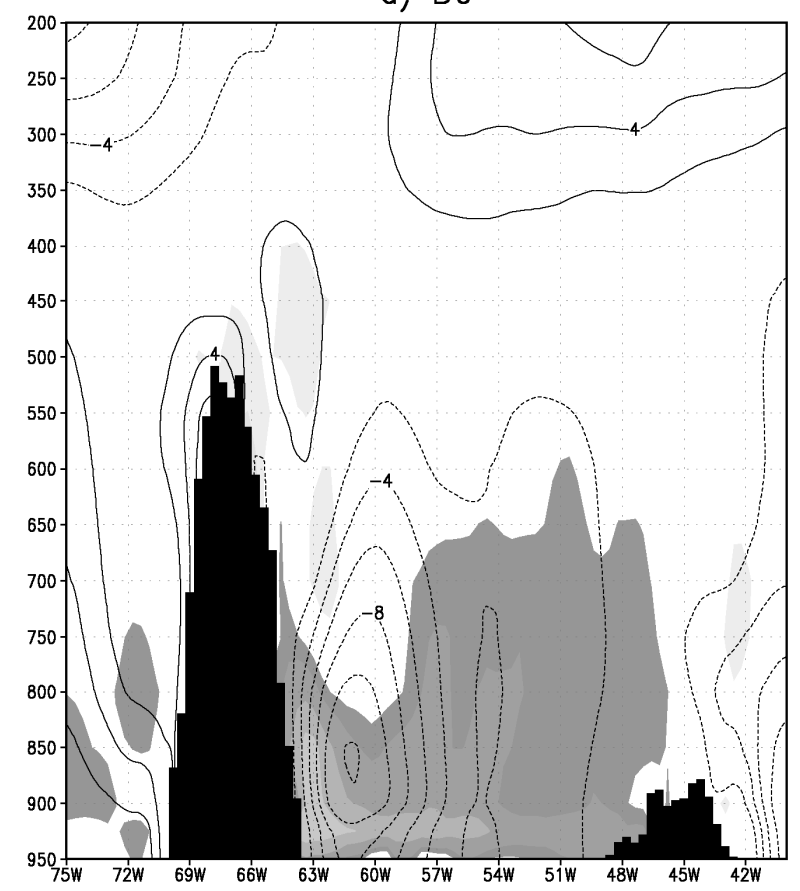

$\begin{array}{llllllllll}-2 & -1.5 & -1 & -0.5 & -0.25 & 0.25 & 0.5 & 1 & 1.5 & 2\end{array}$ b) $\mathrm{AO}$

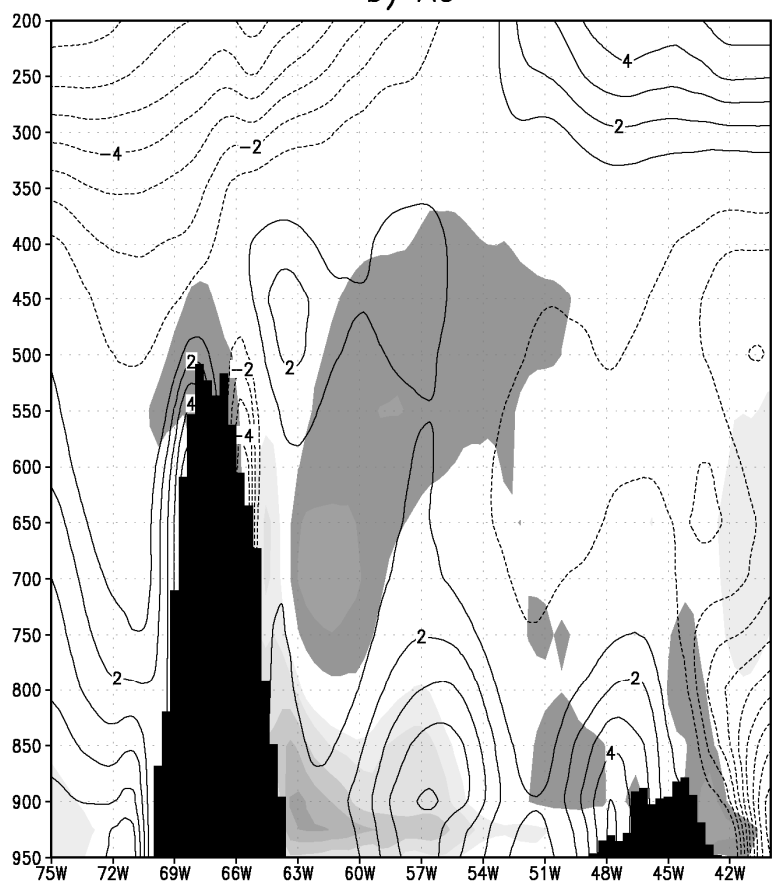

$\begin{array}{llllllllll}-2 & -1.5 & -1 & -0.5 & -0.25 & 0.25 & 0.5 & 1 & 1.5 & 2\end{array}$

Figura 8 - Seção vertical em $22^{\circ} \mathrm{S}$ da componente meridional do vento médio (m/s, contornos, intervalo $2 \mathrm{~m} / \mathrm{s}$ ) e das anomalias de umidade específica ( $\mathrm{g} / \mathrm{kg}$, tons de cinza) para os compostos a) B0 e b) A0. O perfil da topografia é representado pela cor preta.

figuras as tendências da espessura 500/1000 se incluem como referência. Na Figura 10a, pode-se apreciar uma faixa com advecção horizontal quente (calculada no nível de $925 \mathrm{hPa}$ ) localizada aproximadamente sobre $60^{\circ} \mathrm{W}$, a leste da $\mathrm{BCH}$ e estendendo-se para sudeste na região de máximos ventos de norte. Contudo, nas imediações da $\mathrm{BCH}$, e especialmente sobre o centro e oeste da baixa e na retaguarda da frente fria, a advecção predominante é fria como resposta aos ventos de sul e sudeste (ver Figura 5a). A máxima advecção fria detectada na encosta oriental dos Andes, que contrasta com a advecção quente observada na mesma latitude sobre o Oceano Pacífico, é o resultado da influência da Cordilheira dos Andes (Seluchi et al., 2006).

O termo adiabático integrado dentro da camada 500/900 $\mathrm{hPa}$ (Figura 10b) mostra esfriamento por ascensão do ar a leste da Cordilheira dos Andes, aproximadamente ao sul de $20^{\circ} \mathrm{S}$, provocado fundamentalmente pela presença da frente fria e pelo efeito orográfico associado aos ventos de leste. No entanto, a leste e na porção norte da $\mathrm{BCH}$ se observa aquecimento por subsidência, que poderia ter um caráter compensatório, visto que se posiciona entre duas regiões com predomínio de levantamento, localizadas no âmbito da $\mathrm{BCH}$ e em grande parte do Brasil (ver também o campo de Omega na Figura 12).
Essa última região responderia à atividade convectiva típica da estação do ano e do horário analisado (0000 UTC, 21h horário de Brasília).

Os processos diabáticos podem ser analisados com ajuda da Figura 11, que apresenta o campo de precipitação e nebulosidade média diária para o composto B0. A Figura 11a mostra que em média ocorre precipitação na região do Chaco, embora os valores mais anômalos se localizem ao sul da $\mathrm{BCH}$ sobre a região frontal, como foi mostrado na Figura 6a. A liberação de calor latente pela precipitação contribui positivamente para o aumento da espessura e se opõe ao esfriamento provocado pelo levantamento do ar, mostrado na Figura $10 \mathrm{~b}$ e nos contornos da Figura 12. A Figura 11b indica que no momento de máxima intensidade da $\mathrm{BCH}$ a região do Chaco apresenta um mínimo relativo de nebulosidade (menos de $10 \%$ em média). Isso permite deduzir que as precipitações mostradas na Figura 11a, não incidiriam de forma significativa no aumento da nebulosidade sendo, provavelmente, de tipo rápido e convectivo, visto que as chuvas estratiformes são mais típicas de céu encoberto e de mais longa duração. Por outro lado, a Figura $11 \mathrm{~b}$, mostra (em tons de cinza) que a região do Chaco apresenta um mínimo relativo de nebulosidade no composto $\mathrm{B} 0$, associada a uma redução da cobertura de nuvens em relação à véspera 
a) $B-1$

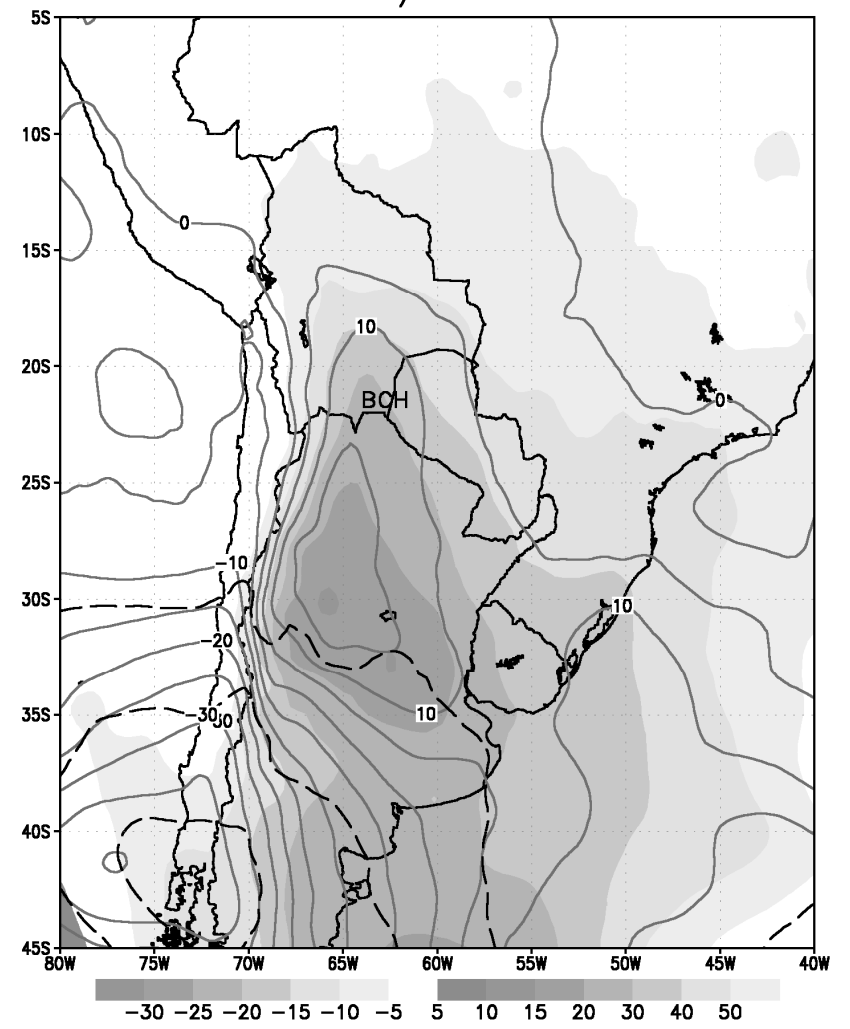

b) $\mathrm{BO}$

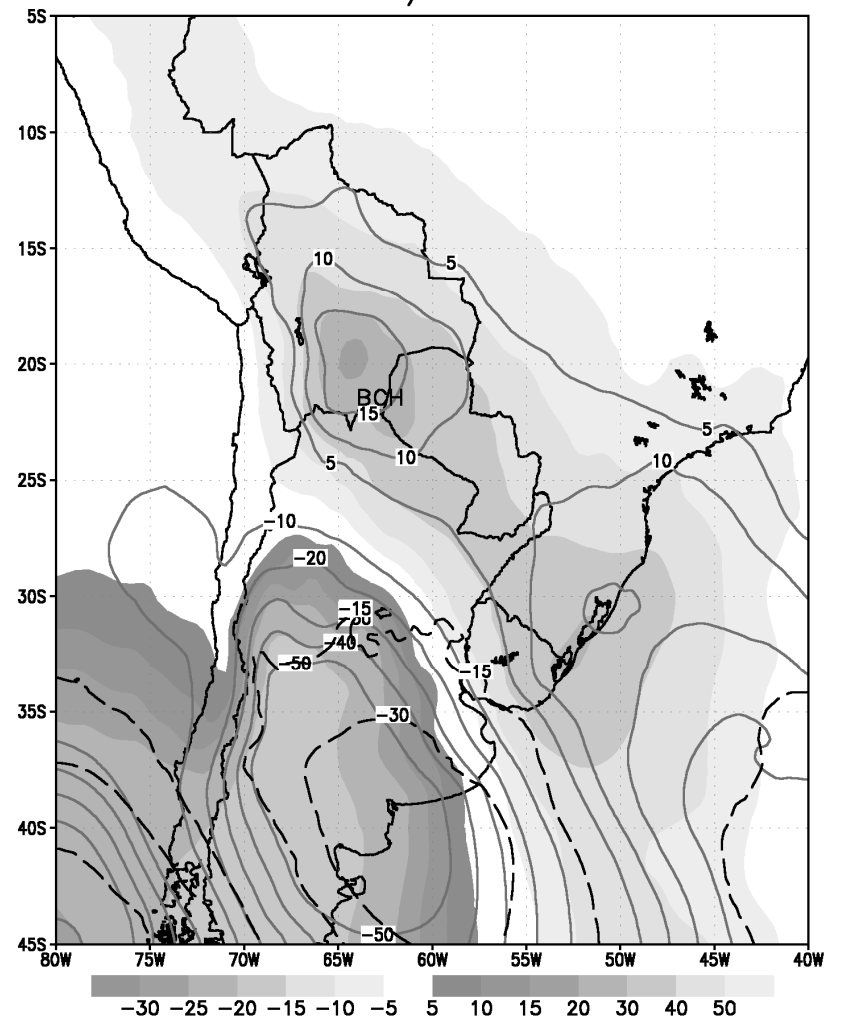

c) B1

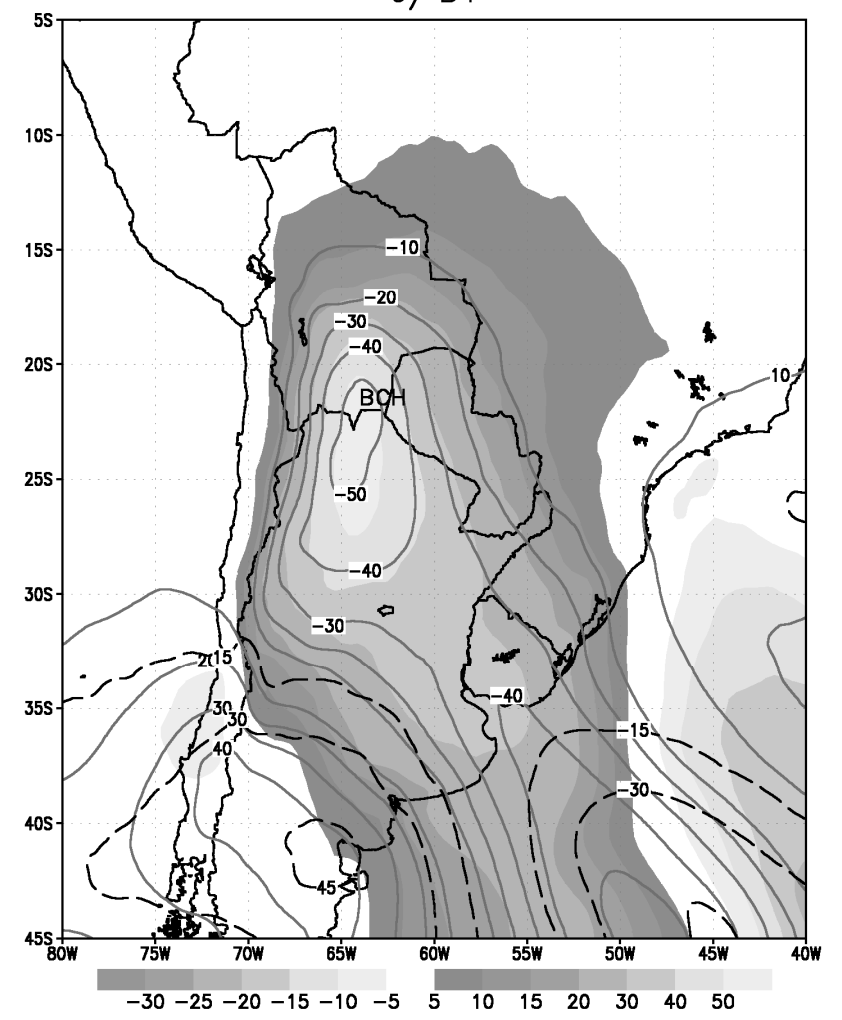

Figura 9 - Campos médios das tendências em $24 \mathrm{~h}$ da altura geopotencial em $1000 \mathrm{hPa}(\mathrm{m} / 24 \mathrm{~h}$, tons de cinza), da espessura 500/1000 (m/24h, linhas grossas cinza, contorno $10 \mathrm{~m} / 24 \mathrm{~h})$ e da altura geopotencial no nível de $500 \mathrm{hPa}(\mathrm{m} / 24 \mathrm{~h}$, linhas tracejadas, contorno $15 \mathrm{~m} / 24 \mathrm{~h})$ para os compostos a) $\mathrm{B}-1, \mathrm{~b}) \mathrm{B} 0$ e c) B1. As tendências foram calculadas como o valor do dia indicado menos o valor correspondente ao dia anterior. 
a)

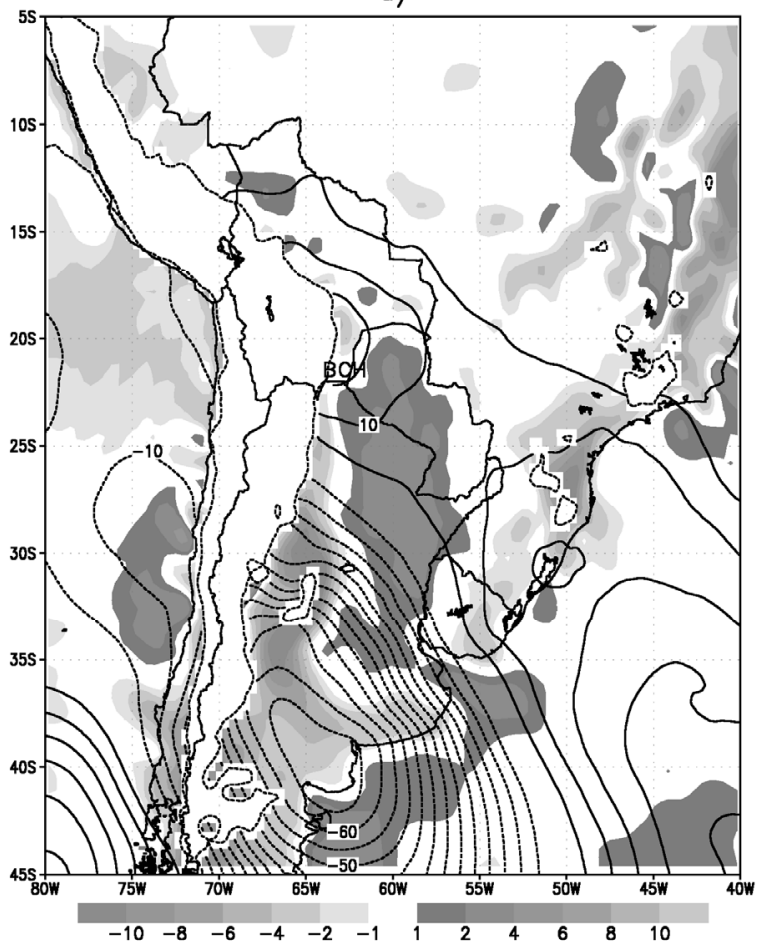

b)

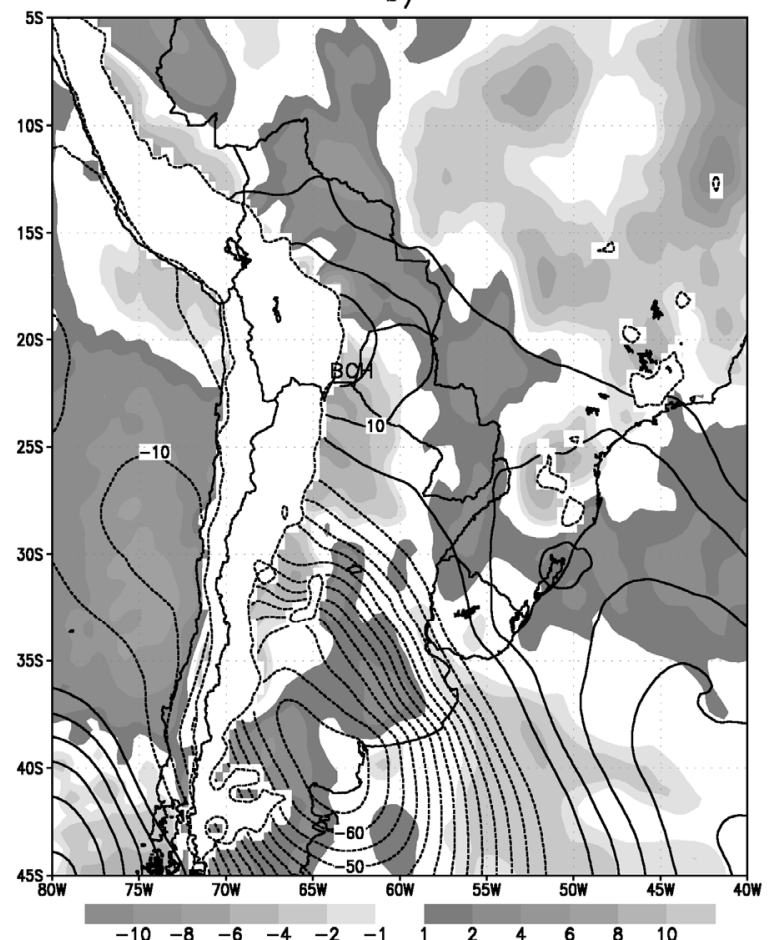

Figura 10 - a) Campo médio de advecção térmica horizontal (oC/dia, tons de cinza) calculada no nível de $925 \mathrm{hPa}$ e b) advecção vertical $\left({ }^{\circ} \mathrm{C} / \mathrm{dia}\right.$, tons de cinza) integrada na camada 500/900 hPa para os compostos B0. Os contornos em ambas as figuras representam a mudança média de espessura em 24hs (m/24h) para os compostos B0. A linha pontilhada delimita a altura topográfica de $700 \mathrm{~m}$, acima da qual os campos foram omitidos.

a)

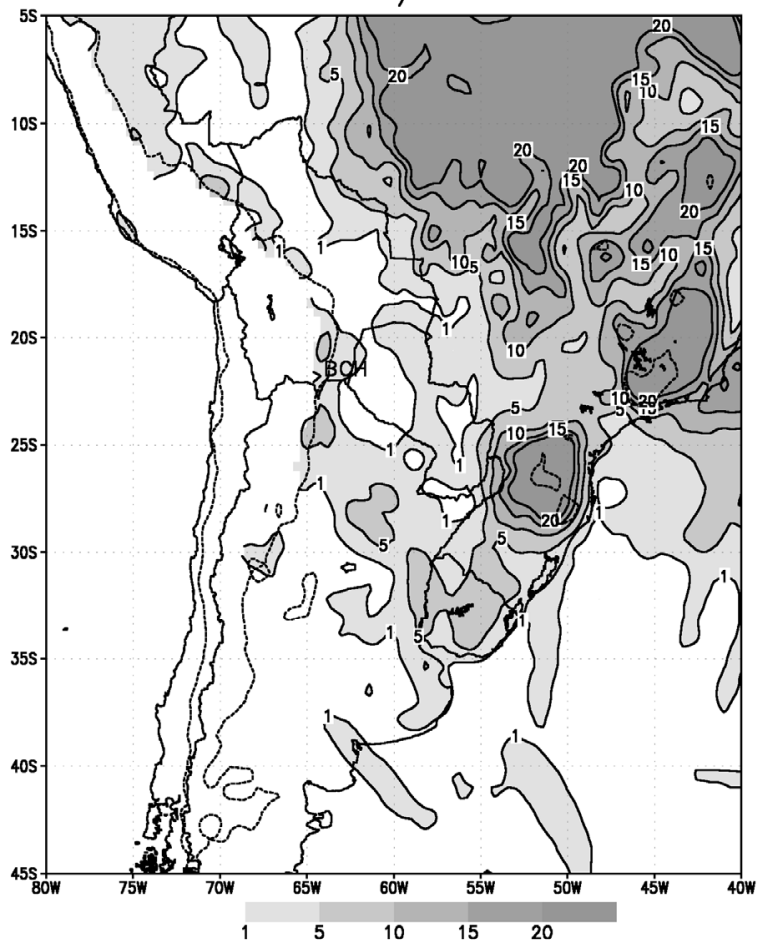

b)

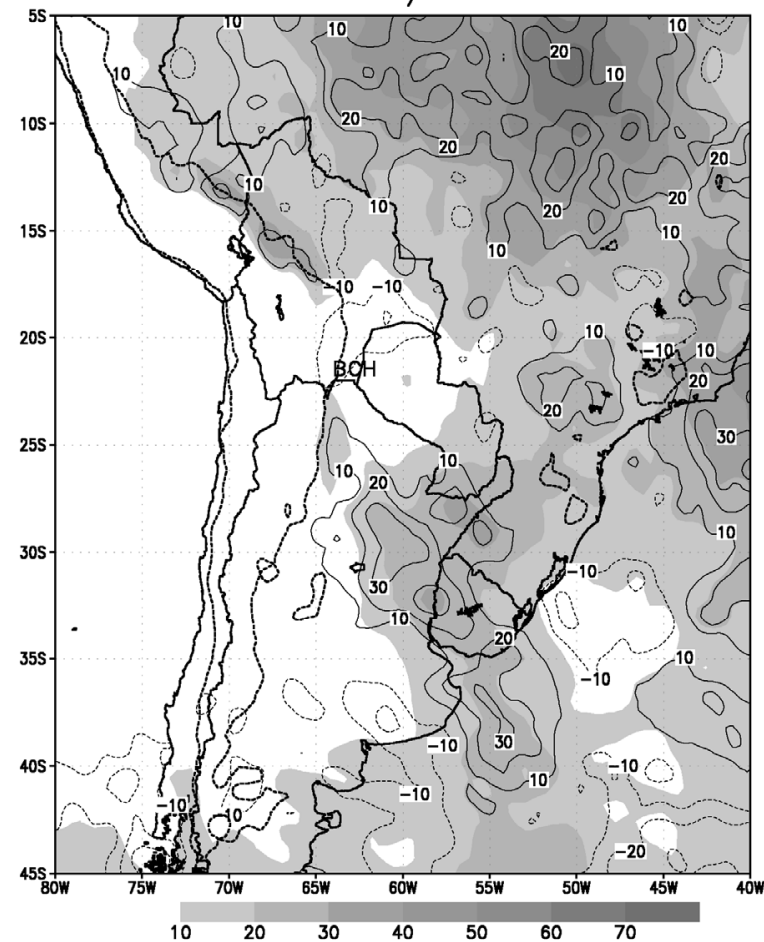

Figura 11 - a) Campo médio de precipitação diária ( $\mathrm{mm}$, tons de cinza) para o composto B0. b) percentagem de céu encoberto (\%, tons de cinza) e tendência média da nebulosidade nas últimas 24 horas $(\% / 24 \mathrm{~h}$, contornos) para o composto B0. A linha pontilhada delimita a altura topográfica de $700 \mathrm{~m}$, acima da qual os campos foram omitidos. 
(contornos). A presença de céu claro, ou pouco nublado, sugere a importância dos fluxos superficiais de calor no processo de desenvolvimento da $\mathrm{BCH}$, como normalmente ocorre na maioria das baixas térmicas. A escassa nebulosidade não impediria, contudo, a ocorrência de chuvas localizadas de tipo convectivo, que são um eficiente mecanismo de liberação de calor latente.

Uma comparação entre as Figuras 10 e 11 aponta uma provável inconsistência, considerando que durante o momento de maior intensidade da $\mathrm{BCH}$, a atmosfera estaria sob influência de movimentos verticais ascendentes (como mostra a Figura 10b) e, simultaneamente, caracterizada por um mínimo relativo de nebulosidade e precipitação (de acordo com a Figura 11). Contudo, a Figura 12 mostra que, mesmo num contexto de movimentos ascendentes, a velocidade vertical $₫$ apresenta anomalias positivas (descendentes) nos dias B0 na região do Chaco, assim como em boa parte da encosta oriental da Cordilheira dos Andes. Em síntese, a redução da nebulosidade e da precipitação está vinculada, em média, a uma diminuição dos movimentos ascendentes.

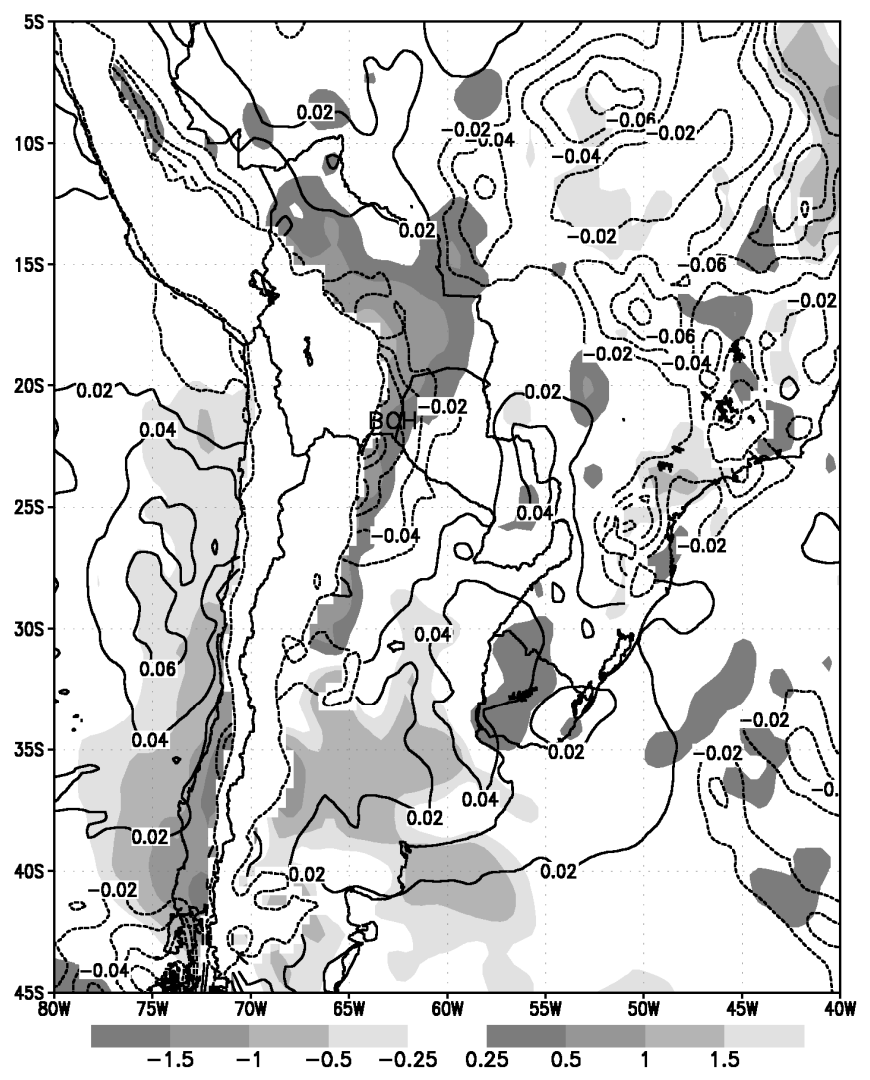

Figura 12 - Campo médio de anomalias de movimento vertical Omega no nível de $700 \mathrm{hPa}$ (tons de cinza, 10-3 $\mathrm{Pa} / \mathrm{s}$ ) e velocidade vertical Omega $(\mathrm{Pa} / \mathrm{s}$ contornos, intervalo $0.02 \mathrm{~Pa} / \mathrm{s})$ para o composto B0. A linha pontilhada delimita a altura topográfica de $700 \mathrm{~m}$, acima da qual os campos foram omitidos.
As Figuras 13 e 14, análogas às anteriores, ilustram os mecanismos físicos atuantes durante o processo de dissipação da BCH (composto B1). Nesse caso, tanto a advecção horizontal de temperatura (Figura 13a), quanto a advecção térmica vertical (Figura 13b) são frias na região do Chaco, contribuindo para a diminuição da espessura 500/1000 hPa e para a consequente dissipação do sistema. Esse padrão obedece à passagem da perturbação frontal (ver Figuras 3, 4 e 5) associada a ventos de sudeste e movimentos ascendentes na região normalmente ocupada pela $\mathrm{BCH}$. Do ponto de vista diabático, a precipitação observada nas proximidades da encosta dos Andes e da região do Chaco (Figura 14a), se opõe ao esfriamento provocado pelos movimentos verticais. Entretanto, o aumento da nebulosidade com respeito à média do dia anterior (Figura 14b) indica que por um lado, as precipitações teriam um caráter mais estratiforme e, por outro lado, os fluxos superficiais de calor têm um papel comparativamente menor em relação ao período de intensificação.

\section{CONCLUSÕES}

O presente trabalho permitiu identificar pela primeira vez na literatura o ciclo de vida da Baixa do Chaco $(\mathrm{BCH})$, relacionado com a passagem de uma perturbação de tipo frontal oriunda das latitudes médias e de escala sinótica ou ainda maior. Essa perturbação afeta toda a troposfera, mas nas latitudes tropicais e subtropicais se manifesta com maior intensidade nos níveis mais baixos da atmosfera.

Durante o ciclo de vida da $\mathrm{BCH}$, o desenvolvimento da BNOA aparece como uma etapa prévia (com defasagem de um dia) à intensificação da $\mathrm{BCH}$. A variabilidade da $\mathrm{BCH}$ está associada a fortes anomalias de temperatura, vento (especialmente na sua componente meridional) e umidade em boa parte da porção tropical e subtropical da América do Sul. A precipitação sofre também alterações importantes em grande parte do continente, mas não apresenta mudanças significativas na região do Chaco. Os campos médios analisados permitem identificar vínculos entre a $\mathrm{BCH}$, a ZCAS e os vórtices ciclônicos em altos níveis característicos do nordeste brasileiro, o que se mostra coerente com a passagem de uma onda de escala regional.

Durante a intensificação da $\mathrm{BCH}$ se verifica um incremento da componente meridional do vento imediatamente a leste da baixa. Em particular, o desenvolvimento da BCH está vinculado, em média, à ocorrência de jatos de baixos níveis, com as decorrentes implicações para o desenvolvimento da atividade convectiva em grande parte do sudeste da América do Sul.

Os processos físicos envolvidos no ciclo de vida da $\mathrm{BCH}$ estão relacionados com passagens de perturbações transientes de origem extratropical, que afetam com maior intensidade as 
a)

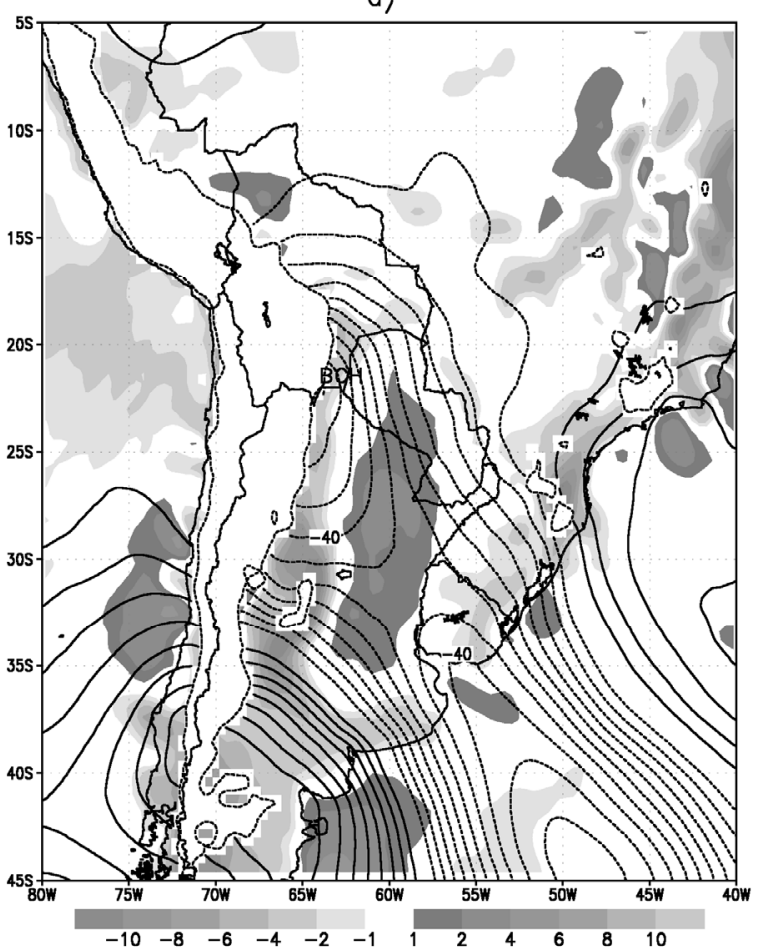

Figura 13 - Idem Figura 10 para os compostos B1.

a)

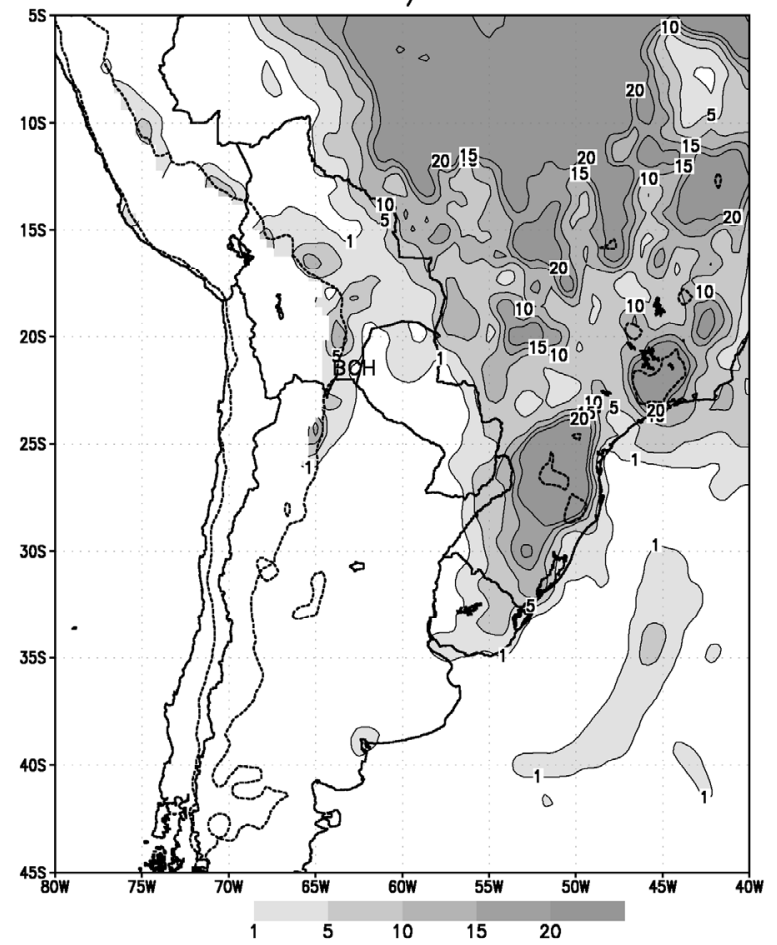

b)

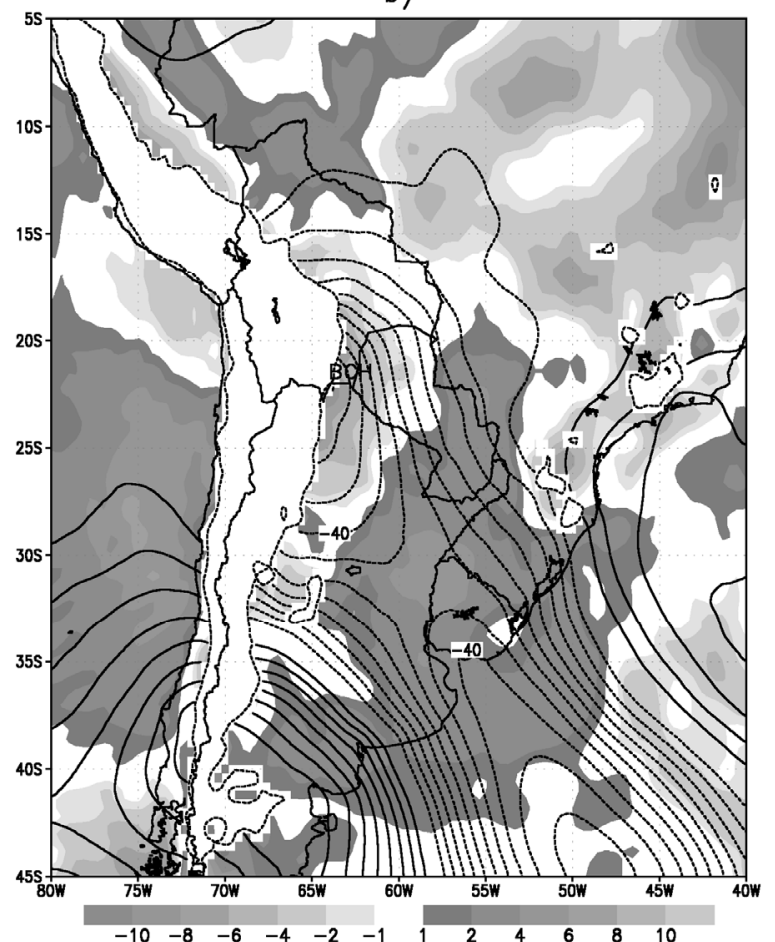

b)

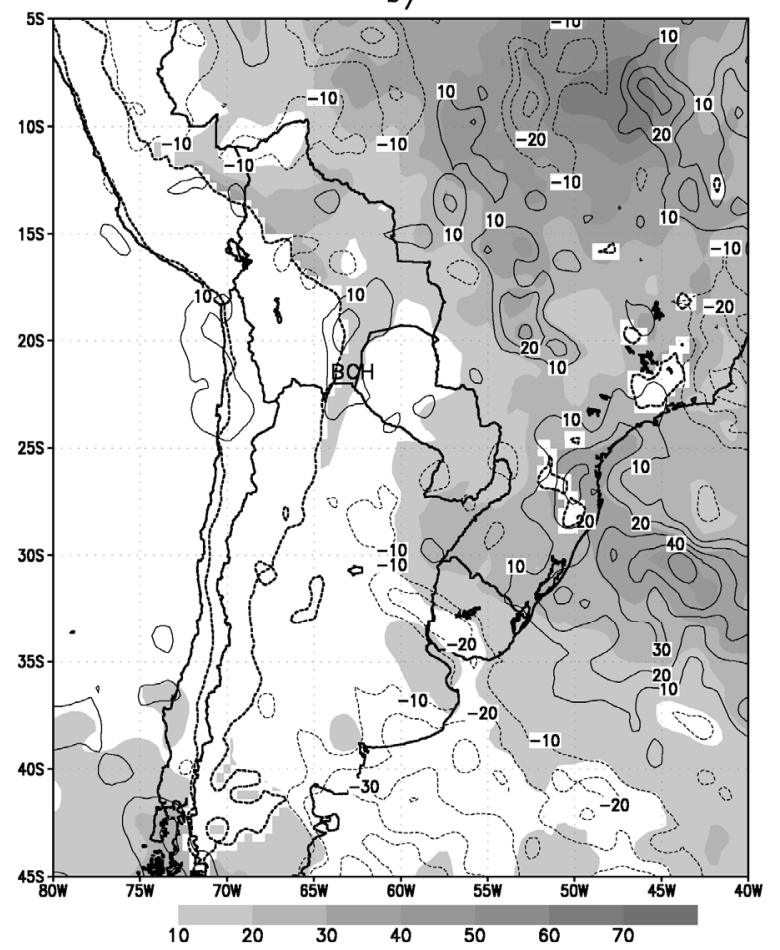

Figura 14 - Idem Figura 11 para os compostos B1. 
latitudes médias do continente, mas que provavelmente devido a sua intensidade e/ou dimensões horizontais, conseguem penetrar até latitudes tropicais. Nesse contexto, a intensidade $\mathrm{da} \mathrm{BCH}$ responde principalmente às variações da espessura (ou temperatura) na camada 500/1000 na região do Chaco, e em menor medida às variações da altura geopotencial associadas à passagem de perturbações nos altos níveis. Entre os mecanismos físicos diretamente responsáveis pela intensificação da $\mathrm{BCH}$, vinculados à aproximação de uma perturbação frontal, pode-se identificar a precipitação do tipo convectiva (que provoca liberação de calor latente) e a presença de céu claro (com menos de $10 \%$ de cobertura), que permite fortes fluxos superficiais de calor. Esse último mecanismo pode estar vinculado à presença de subsidência anômala (levantamento menor que a média) que, contudo, não inibe completamente a ocorrência de precipitação na região de interesse, provavelmente como resultado dos altos valores de temperatura e umidade. Os processos advectivos não parecem contribuir, pelo menos em média, para a intensificação da $\mathrm{BCH}$. Em particular a advecção térmica horizontal na região do Chaco não tem um sinal definido, enquanto que a advecção vertical dominante resulta fria como consequência dos movimentos de levantamento do ar.

Os processos físicos atuantes durante o período de dissipação da $\mathrm{BCH}$ estão associados à aproximação de um sistema de alta pressão com características pós-frontais. Nesses casos, a dissipação da $\mathrm{BCH}$ resulta da combinação da advecção horizontal e vertical frias, além da presença de céus mais encobertos em relação ao período de intensificação. A maior cobertura de nuvens é provavelmente resultado da interação entre os ventos de sudeste e a presença da encosta da Cordilheira dos Andes.

Embora tenha se mostrado neste trabalho que o ciclo de vida da $\mathrm{BCH}$ está relacionado à atuação de perturbações de tipo frontal compatíveis espacialmente com a escala sinótica, não é possível afirmar que a variabilidade temporal desta baixa responda a essa escala. Tal hipótese deriva tanto da experiência diária como de estudos prévios (Cavalcanti e Kousky, 2009), que mostram que durante a estação chuvosa (durante a qual se desenvolve a $\mathrm{BCH}$ ) a frequência de passagens frontais sobre latitudes subtropicais e tropicais da América do Sul é relativamente baixa (menos de uma/mês) e resulta da combinação de trens de onda de grande amplitude e de escala maior à sinótica (Garreaud e Wallace, 1998). Por essa razão a análise da variabilidade temporal da $\mathrm{BCH}$ será alvo de um estudo futuro.

\section{AGRADECIMENTOS}

Os autores agradecem os valiosos comentários do Dr. Manoel Alonso Gan e do revisor anônimo que ajudaram a melhorar o artigo. Este trabalho foi parcialmente financiado pelo Conselho de Desenvolvimento Científico e Tecnológico (CNPq) por meio do Projeto Prosul (CNPQ/490225/2008-0).

\section{REFERÊNCIAS}

ANDREOLI, R. V.; HERDIES D. L.; SOUZA R. A.; SAPUCCI L. F.; ARAVÉQUIA J. A.; FERREIRA S. H. S., Tipos de observações e o controle de qualidade utilizado na assimilação de dados no CPTEC/INPE. Boletim da Sociedade Brasileira de Meteorologia, v. 32, p. 65-70, 2008.

ARAVEQUIA, J. A.; HERDIES D. L.; SAPUCCI L. F.; ANDREOLI R. V.; FERREIRA S.H.S.; GONÇALVES L. G.G. Reanálise Regional 2000-2004 sobre a América do Sul com o Modelo RPSAS/ETA: Descrição do Experimento e dos Produtos Derivados. Boletim da Sociedade Brasileira de Meteorologia, v. 32, p. 71-77, 2008.

BONNER W. D., Climatology of the low level jet. Monthly Weather Review, v. 96, p.833-850. 1968.

CARVALHO, L; JONES C. Tempo e Clima no Brasil. Cap 6: Zona de Convergência do Atlântico Sul. Oficina de Textos. 2009

CAVALCANTI, I. F.A.; KOUSKY V. E., Tempo e Clima no Brasil. Cap 9: Frentes frias sobre o Brasil. Oficina de Textos. 2009.

GAN, M. A.; KOUSKY; V. E.; ROPELEWSKI; C. F., The South America Monsoon Circulation and Its Relationship to Rainfall over West-Central Brazil. Journal of Climate, v.17, p 47-66, 2004

GAN, A. M.; RAO B. V. The influence of the Andes Cordillera on transient disturbances. Monthly Weather Review, v. 122, p.1141-1157, 1994.

GARREAUD, R.D.; WALLACE, J. Summertime Incursions of Midlatitude Air into Subtropical and Tropical South America, Monthly Weather Review, v. 126, p.2713-2733, 1998.

FERREIRA, L.: Causas y variabilidad de la Depresión del Noroeste Argentino e Impactos sobre los Patrones Regionales de Circulación. 177f. 2008. Tese de Doutorado. Universidade de Buenos Aires.

HERDIES, D. L.; ARAVEQUIA J. A.; FERREIRA S.H.S. ; ANDREOLI R. V. ; SAPUCCI, L. F. ; MATTOS, J. G. Z. A Assimilação de Dados no CPTEC/INPE. Boletim da Sociedade Brasileira de Meteorologia, v. 32, p. 57-64, 2008.

KOUSKY, V. E.; GAN M.A. Upper tropospheric cyclonic vortices in the tropical South Atlantic. Tellus, v. 33, p.538551,1981

LENTERS, J. D.; COOK K. H.: Summertime Precipitation Variability over South America: Role of the Large-Scale 
Circulation. Monthly Weather Review, v.127, p.409-431, 1999.

LiCHTENSTEIN, E.R., La Depresión del Noroeste Argentino, 223f. 1980. Tese de doutorado, Universidade de Buenos Aires.

MARENGO J.; SOARES W.; SAULO A.C.; NICOLINI M. Climatology of the Low-Level Jet East of the Andes as Derived from the NCEP-NCAR Reanalyses: Characteristics and Temporal Variability. Journal of Climate, v. 17, n. 12, p.2261-2280, 2004

MESINGER F. A blocking technique for representation of mountains in atmospheric models. Rivista di Meteorologia Aeronautica, v.44, p. 195-202, 1984.

PAEGLE J.N; MO K.C. Alternating Wet and Dry Conditions Over South America during Summer. Monthly. Weather Review, v.125, P.279-290, 1997.

SALIO, P.; NICOLINI, M.; SAULO, A.C. Chaco Low-Level Jet Events Characterization During the Austral Summer Season by ERA Reanalysis. Journal of Geophysical Research v. 107, D24, 4816, 2002, doi: 10.1029/2001JD001315

SATYAMURTY, P.; NOBRE, C. A.; SILVA DIAS, P.L., Meteorology of The Southern Hemisphere. Chapter 3C, v. 27, n. 49, p. 119-139, American Meteorological Society, 1998.

SAULO A.C.; SELUCHI M.E; NICOLINI M. A Case Study of a Chaco Low Level Jet Event Monthly Weather Review v. 132, n. 11, p. 2669-2683, 2004.

SCHWERDTFEGER, W.C. Análisis sinóptico y aspecto climatológico de dos distintos tipos de depresiones báricas sobre el Norte de la Argentina, Meteoros, v. 4, p 301-323, 1954
SELUCHI, M. E.; GARREAUD, R; NORTE F.; SAULO A.C., Influence of the Subtropical Andes on baroclinic disturbances: A cold-front case study. Monthly Weather Review. v.134, p. 3317-3335, 2006.

SELUCHI M.E.; SAULO, A. C.; NICOLINI, M.; SATYAMURTY P.: The Northwestern Argentinean Low: a study of two typical events. Monthly Weather Review, v 131,p. 2361-2378, 2003.

SELUCHI M.E.; SAULO A.C.: Mecanismos físicos associados à formação da Baixa do Chaco. Anais do XVI Congresso Brasileiro de Meteorologia, Anais. Belém, 2010, 1 CDROM.

SELUCHI M.E.; SAULO A.C.; GARREAUD R.D., Baixa termo-orográfica e Baixa do Chaco: dois sistemas diferentes? Anais do XVI Congresso Brasileiro de Meteorologia, Anais.. Belém, 2010, 1 CD-ROM.

SELUCHI M.E.; SAULO A.C.; Baixa do Noroeste Argentino e Baixa do Chaco: Características, diferenças e semelhanças. Revista Brasileira de Meteorologia. v.27, n.1, 49-60, 2012. VERA C.; HIGGINS W.; AMADOR J.; Ambrizzi T.; GARREAUD R.; GOCHIS D.; GUTZLER D.; LETTENMAIER D.; MARENGO J.; MECHOSO C.; J. NOGUES-PAEGLE J.; DIAS P.L.S.; ZHANG C. Toward a Unified View of the American Monsoon Systems. Journal of Climate, v.19, p.4977-5000, 2006. 